Portland State University

PDXScholar

Winter 2-23-2015

\title{
School Culture and the Affective Learning Needs of Latino Long-term English Learners
}

Maureen Ray

Portland State University

Follow this and additional works at: https://pdxscholar.library.pdx.edu/open_access_etds

Part of the Educational Leadership Commons, and the Educational Methods Commons Let us know how access to this document benefits you.

\section{Recommended Citation}

Ray, Maureen, "School Culture and the Affective Learning Needs of Latino Long-term English Learners" (2015). Dissertations and Theses. Paper 2209.

https://doi.org/10.15760/etd.2206

This Dissertation is brought to you for free and open access. It has been accepted for inclusion in Dissertations and Theses by an authorized administrator of PDXScholar. Please contact us if we can make this document more accessible: pdxscholar@pdx.edu. 
School Culture and the Affective Learning Needs of Latino Long-term English

Learners

by

Maureen Ray

A dissertation submitted in partial fulfillment of the requirements for the degree of

\section{Doctor of Education}

in

Educational Leadership: Curriculum and Instruction

Dissertation Committee:

Dannelle D. Stevens, Chair

Esperanza De La Vega

Samuel Henry

Lynn Santelmann

Portland State University

2015 
(C) 2014 Maureen Ray 


\begin{abstract}
The US Department of Education projects that by the year 2030 the total English Learner (EL) population in US schools will exceed 40 percent. Currently, by the time ELs make it to high school, after 7 or more years in English Language Development (ELD) programs, the majority (59 percent), are Long Term English Learners (LTEL). LTEL students represent a variety of ethnicities and language groups, but the focus of this qualitative study is LTEL students who identify as Latino LTEL. The purpose of this qualitative study was to describe and explain recently graduated Latino LTEL's perceptions of the impact of their school's culture on their academic and affective acculturation. As schools look to improve the educational outcome of Latino EL, listening to voices of former LTEL as they share their high school experiences can provide insights into ways to support the affective learning needs, academic success, and acculturation of Latino EL. Through 10 in-depth interviews with former Latino LTEL and employing qualitative coding analysis, this research explored and analyzed recently graduated Latino EL's perceptions of the impact of school culture on their academic acculturation. Even though schools have for many years attempted to address the needs of their linguistically diverse students, the results of this study indicate that the participants' high schools did not do enough to support their academic and affective learning needs. This lack of support impacted participants' self-perceptions of themselves as learners. To
\end{abstract}


bridge Latino LTEL acculturative gaps, the findings support the need for school cultures to address the affective learning needs of their bi-cultural and Latino EL. 


\section{Dedication}

This endeavor is dedicated to my daughter, Michele Ananda Ray Stephenson. I miss you with my entire heart and soul. 


\section{Acknowledgements}

This research would not have been possible without the participants' participation. I appreciate their taking their time to meet with me and their trusting me to represent their voices, perspectives and experiences.

I also appreciate the time that my dissertation committee has taken to ensure that my dissertation meets the rigor and requirements of our field. Thank you Dannelle Stevens, Esperanza De La Vega, Samuel Henry, and Lynn Santelmann.

Thanks also to Stefanie Randol for guiding me through the program's requisites.

Finally, Matt Mattia thank you for your keeping me grounded. 


\section{Table of Contents}

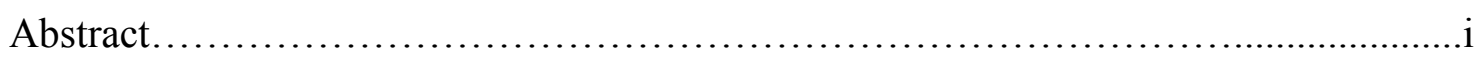

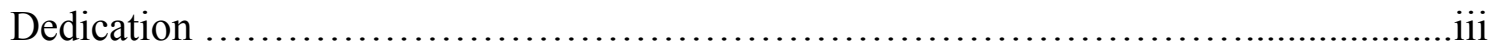

Acknowledgements ...............................................................

List of Tables .......................................................................

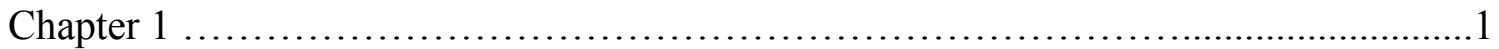

My Interest in the Affective Learning Needs of Latino Long-term EL ................1

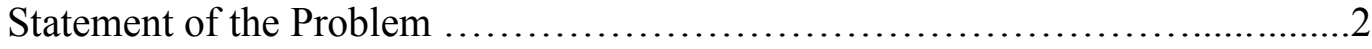

Characteristics of Latino LTELs................................................

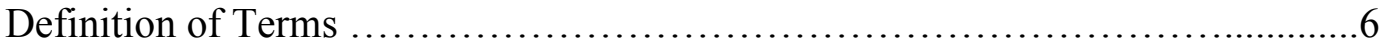

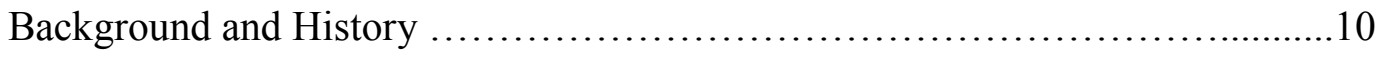

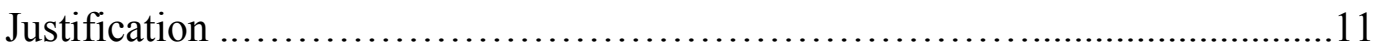

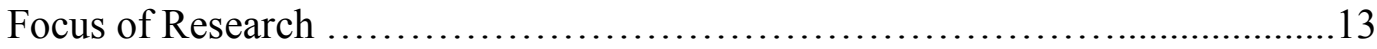

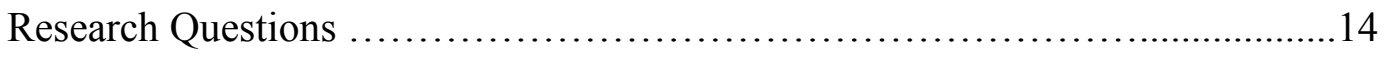

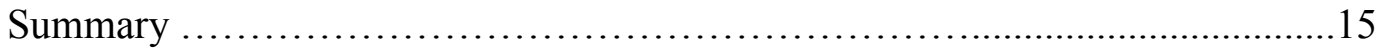

Chapter 2

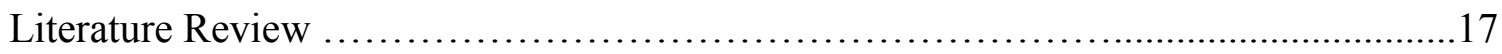

Language Learning and Metaphors .............................................19

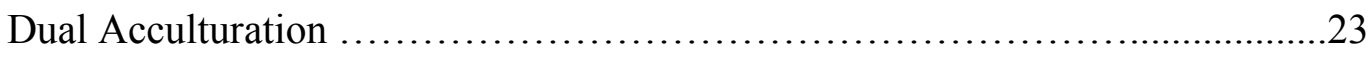

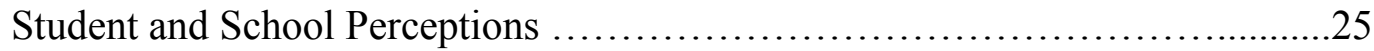

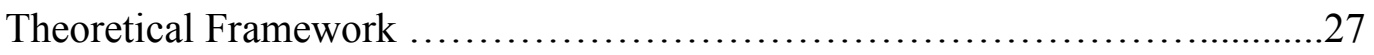




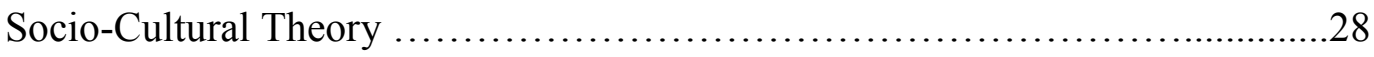

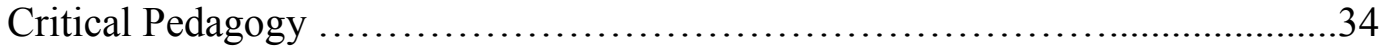

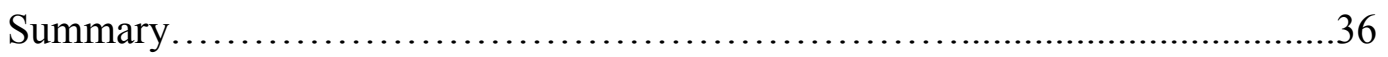

Chapter 3

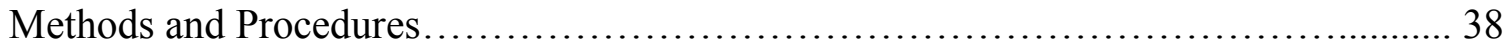

A Qualitative Approach .............................................. 38

Data Gathering............................................................. 40

Data Analysis............................................................. 48

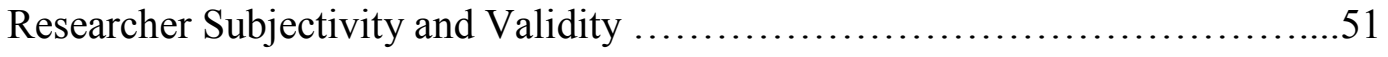

Confidentiality, Records \& Distribution ...................................54

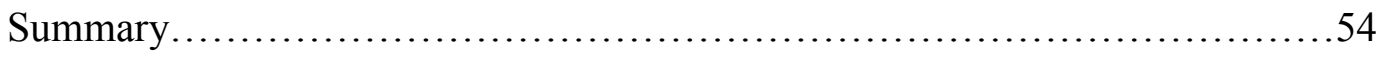

Chapter 4

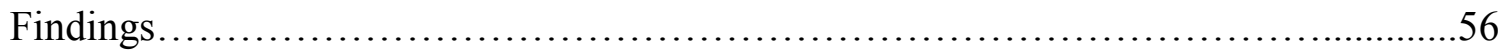

Participant Characteristics .........................................57

Participant Interviews..............................................62

Code Family Themes..............................................63

Participants' Suggestions for Supporting Latino LTEL's Academic and Affective

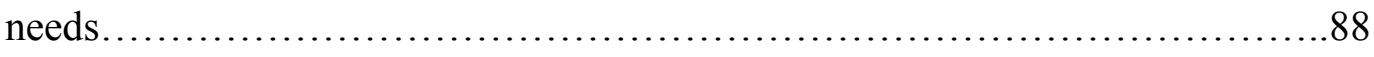

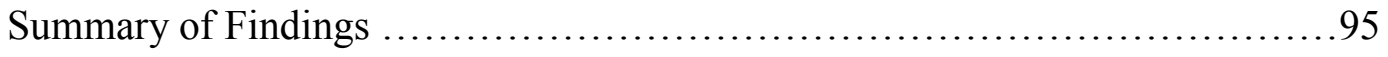

\section{Chapter 5}

Discussion of Findings ................................................. 97

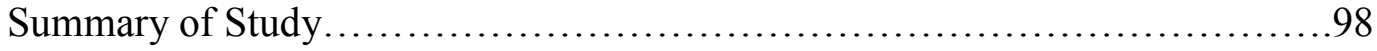

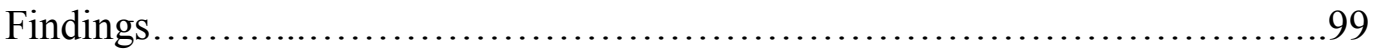




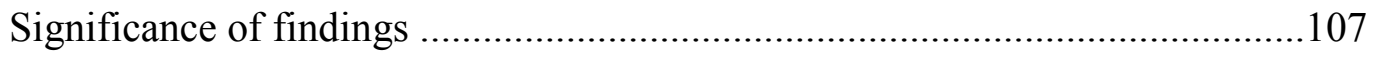

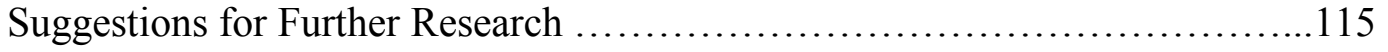

Summary and Conclusion ...........................................116

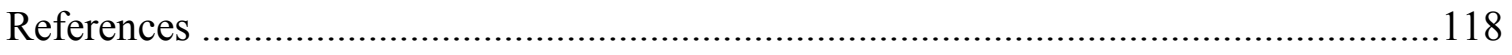

Appendix A - Participant Informed Consent ...............................................129

Appendix B - Questions for semi-structured interviews........................................131

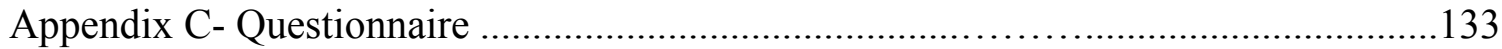

Appendix D - Email Recruitment Letter .......................................................135

Appendix E - Code Families With A List Of Their Codes And Number Of Quotes .....137 


\section{List of Tables}

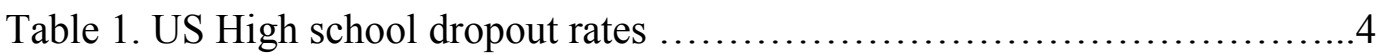

Table 2. Latino dropout rates in the US .................................4

Table 3. Interview questions and themes from the research questions $\ldots . \ldots \ldots . .58$

Table 4. Participant ethnicity and socio-economics...........................56

Table 5. Participants' education background...............................61

Table 6. Summary of participant characteristics. ...........................62

Table 7. Thematic code families.........................................65 


\section{Chapter 1}

\section{My Interest in the Affective Learning Needs of Latino Long-term ELS}

During my first year of teaching high school English Learners (EL), in the Pacific Northwest of the US, it became clear to me that many of my EL students were born in the US, or they had moved here early in their lives or school career. Some of them had been in US schools since kindergarten. As I worked with my students that first year, it appeared that many of them would likely be graduating from high school as EL students and would be taking ELL classes during their first years of college. I began wondering why so many students, after 7-12 years in our school system, were remaining in English Language Development (ELD) programs.

Further inquiry revealed that the EL students in my district were not an anomaly. Throughout the US, a majority of English language learners experience similar trajectories (Olsen, 2010; Olsen \& Wan; 2010). I discovered these students are referred to in current education research literature as Long-term English Learners (LTELs) (Hakuta, 2000; Olsen 2010; Olsen \& Wan; 2010). LTELs are students born in the US or who started elementary school in US, received ELL services in elementary school and then continue receiving services through high school (Cummins, 2000;Hakuta, 2000; Harklau, 2003; Olsen, 2010). 
That first year of teaching EL, as I got to know my students, I became aware that many of my LTEL students were, in some ways, ill at ease in school, and struggling to acculturate to the school's community. They expressed in a range of ways how they didn't feel part of the school culture, and as such didn't participate in any schoolsponsored extracurricular activities. There were varieties of school activities available-student government, dance teams, school sports, but none that the students in our ELL program chose to join. This reluctance on the part of my students troubled me and left me with many questions that spurred my interest in researching the issues regarding the acculturation of Latino Long-term English Language learners into high school.

The purpose of this study was to describe and explain recently graduated Latino Long-term English learners' perceptions of the impact of their school's culture on their academic and acculturation. The rest of this chapter begins with a statement of the problem; I will then turn to defining key terms that I will employ in the discussion of Long Term ELs throughout this study. The section following the statement of the problem will provide a short background history about immigrants and education. The last sections of this chapter focus on the justification for this research and a discussion of my primary research questions.

\section{Statement of the Problem}

English Learners (ELs) are the fastest growing sector of student population in the United States (US Dept. of Education, 2012). Between 1979 and 2008, the number of school-aged children who spoke a language other than English at home increased from 9 
to 21 percent (US Dept. of Education, 2012). In the US, on average, the majority (59 percent) of English Language Learners in high school are Long Term ELs (Goldschmidt \& Miller 2005; Harklau, 2003; Olsen, 2010).

Schools across the nation are providing English Language Development (ELD) classes; however, a majority of EL students are not developing academic proficiency and are often either graduating from high school unprepared for college or dropping out without receiving a high school diploma (Olsen, 2010). Table 1 shows that in 2009, the high school dropout rate for Latino youth, who comprise the majority of ELs throughout the US, was 17.6 (Chapman, Laird, \& KewalRamani, 2010). It is not acceptable that approximately 18 percent of our Latino student population is not receiving an education that will enable them to be successful members of our society. Latinos have the highest dropout rate of all the ethnic groups reported. It is projected that by the year 2030 the total EL population in US schools will exceed 40 percent (Olsen, 2010).

When studying the dropout rate for Latino students the US Department of Education has added another level of complexity (Chapman, Laird, \& KewalRamani, 2010). The overall dropout rate for Latinos is 17.6 percent; however, the Department of education also disaggregated the dropout rate for immigrant, first generation, and second generation and beyond Latinos. Table 2 shows the dropout rates for all Latinos in the US, for immigrant Latinos, and first and second generation Latinos. First generation Latinos are considered those born in the US but their parents were born outside of the US. Second 
generation and beyond students were born in the US as were their parents. The majority of Latino LTEL students fall into the immigrant Latino and first generation category.

Table 1.

US high school dropout rates

\begin{tabular}{|c|c|}
\hline Ethnicity & Dropout rate \\
\hline White & $5.2 \%$ \\
\hline Black & $9.3 \%$ \\
\hline Hispanic & $17.6 \%$ \\
\hline Asian/Pacific Islander & $3.4 \%$ \\
\hline Native American & $13.2 \%$ \\
\hline \multicolumn{2}{|c|}{$\begin{array}{l}\text { Table } 1 \text { and } 2 \text { Source data: Chapman, Laird, \& KewalRamani, for Nationa } \\
\text { Center for Education Statistics } 2010\end{array}$} \\
\hline \multicolumn{2}{|l|}{ Table 2.} \\
\hline \multicolumn{2}{|c|}{ Latino high school dropout rates in the US } \\
\hline Latino Group & Percent who dropout \\
\hline All Latinos in US schools & $17.6 \%$ \\
\hline Immigrant Latinos & $31.3 \%$ \\
\hline First generation Latinos & $11.8 \%$ \\
\hline $2^{\text {nd }}$ generation Latinos & $10.2 \%$ \\
\hline
\end{tabular}

\section{Characteristics of Latino LTELs}

Throughout the US, school districts have varying measures they use to determine a student's level of English language development. When they reach a level of English language proficiency that the district has determined is sufficient, they are exited from receiving ELD services. LTELs are students born in the US or who started grade school in the US, received ELL services in grade school and continued receiving services in high school (Cummins, 2000; Harklau, 2003: Olsen, 2010; Olsen \& Wan; 2010). Many of these students, even though born in the US, did not begin to speak English until they 
entered kindergarten or later. In general, the literature considers students who have participated in ELD programs for seven years or longer, are no longer progressing towards English proficiency and struggle academically, LTELs (Collier, 1995; Collier \& Thomas, 1989; Cummins, 2000; Hakuta, 2000; Olsen, 2010).

LTELs do not have sufficient academic English skills needed for academic success, and they have accumulated major educational gaps in their elementary school and/or middle school years. LTEL students often appear to be native speakers of English, they usually speak without an accent, their social English is fluent, but their academic English skills are less developed than their peers and this can lead to their struggling academically (Collier \& Thomas, 1989; Hakuta, 2000; Olsen, 2010). LTEL are considered long-term because they have not achieved a sufficient level of academic English necessary to meet their school's criteria for exit out of their ELD programs. It is not uncommon that an insufficient level of academic English over years causes classroom instruction to be difficult to access, hence many LTEL "have developed habits of nonengagement, learned passivity, and invisibility in school" (Olsen, 2010, p. 2).

Language theories associated with learning a foreign language demonstrate the importance of students receiving or having received schooling in the language spoken in their home (Collier, 1995; Cummins, 2000; Krashen, 1982). They propose that it usually takes up to ten years for a student who has not received schooling in their home language to achieve academic language proficiency. Whereas, students who have had academic schooling in their own home language usually attain academic language proficiency 
within 5-7 years (Collier, 1995; Cummins, 2000; Olsen, 2010). ELD programs have testing and exiting criteria to determine whether a student's English proficiency is sufficient to exit them from ELD services. For example, in my school district the exiting of students from ELD follows a protocol. A student is exited from ELD whereupon a panel, of three or more ELD and core teachers, has examined their school records, their state reading scores, several writing work samples and their state English Language Proficiency Assessment (ELPA) scores. Students are retained in ELD programs until they are determined to have met the districts' or states' exit criteria of sufficient English language proficiency.

Definition of Terms. It is helpful to understand the historical and socio-cultural origins of some of the terms that I will be using to discuss processes of integration that English language learners undergo when they enter schools in the US. As academics, the words we use to define groups, processes, and concepts invoke certain suppositions that inform and underpin our assumptions and expectations about how we make sense of our subject of inquiry, and how we convey this sense to others (Calhoun, 1994; Lantolf, 1994; Urrieta, 2007; Vygotsky, 1962). Hence, in order to facilitate a deeper understanding of the issues that are presented in this chapter and throughout this study, I will define and explain a few of the terms and concepts that I will be employing in this study. Some of these terms originate from within fields of linguistics as well as other research fields of social science that study immigrants and immigrant students' processes of adaptation and integration to the host culture or society. 
Acculturation: Acculturation refers to the varying degrees of adaptation and integration that occur when two cultures are in long-term contact; historically it also recognizes the reciprocal nature of cultural change when two or more culture groups come into contact (Berry, 1997; 2003). It is now commonly accepted that immigrants fare better when they retain their first culture, but adapt behaviors that enable them to successfully navigate a new culture (Berry, 1997; Deters, 2011; Trimble, 2003).

The concepts behind the term have changed much since its first use in anthropology, but there is current research that recognizes the dual nature of the adaptation that occurs between immigrants and host communities. In the case of this research, the host culture is the schools to which immigrants enter (Berry, 1997; Ray, 2003; Lave, 1996; Trimble, 2003). Acculturation theory indicates that culture groups change when in contact with other culture groups. However, the degree of change and adaptation involved for each culture is often not equal, as there may be unequal power dynamics between the host culture and an immigrant's culture of origin.

Affective needs. When exploring the ways Latino LTEL adapt to local school cultures, it is relevant to consider how LTEL's emotional, psychological and social realities impact their adaptation (Combs, 1982; Faircloth, 2009). To this end, we refer to the affective needs of students. Elements of students' affective needs include: sense of belonging, a positive sense of themselves as learners, and feeling represented in the school's culture (Collier, 1995; Combs, 1982; England, 1982; Faircloth, 2009; Krashen, 1982; Lalas \& Valle, 2007; Volet, 1997). 
Prior research indicates positive school affect, such as a sense of belonging, feeling valued and cared for, positively impacts students' motivation, engagement and achievement (Combs, 1982; Faircloth \& Hamm, 2005; Faircloth, 2009; Milner 2002; Osterman, 2000; Volet, 1997). Krashen (1982) and Cummins (2000), in their hypotheses of second language learning, also refer to the affective needs of English learners. Both Krashen and Cummins view the overarching affective needs of language learners as a safe and supportive learning environment where students feel comfortable taking risks, they posit that when student's affective filters are lowered, language learning occurs more efficiently. Conversely some socio-cultural research on affective needs indicates that when language learners are stressed language acquisition will be impeded (Aronson, 2004; Combs, 1982; Faircloth, 2009; Faircloth \& Hamm, 2005; Milner 2002; Steele \& Aronson, 1995).

Assimilation. Historically referred to as the melting pot theory, assimilation describes the process where an immigrant fully integrates and conforms to not only the language of the new culture but its values, behaviors, traditions and lifestyle (Berry, 2003; Garcia-Vasquez, 1995). Historically, assimilation was viewed as a one-way relationship: that is, while American society shaped immigrant ethnic groups, the cultures of its immigrant population would not shape America. Adherents to an assimilationists belief system take for granted that over time an immigrant would no longer identify with their original culture and become Americanized (Portes, 1997). 
The US is a country that was settled by both voluntary and involuntary immigrants (Gibson, 1997; Ogbu, 1993). Much of the early literature that examined immigration processes and integration of immigrants in the US originated during the late 1800s in the fields of sociology and anthropology. This early work studied integration of European ethnic groups into society and analyzed how the cultures of both groups were changed through the resulting cultural interaction (Trimble 2003; Berry 2003; Gans 1997). In the 1920s, in response to demographic shifts caused by a new wave of immigration (from southern and Eastern Europe) researchers began studying the Americanization of immigrant groups (Rumbaut, 1999). Much of this early literature on immigration assumed all ethnic groups would, over a period of time (generally considered to be three or four generations), assimilate into the dominant culture. They observed an immigrant process of 'assimilation' and extrapolated this assimilative process of integration to all ethnic immigrant groups. This assumption that all immigrants would assimilate influenced how the US approached the education of immigrants for most of the twentieth century.

Berry (1997) explains that assimilation is not always a positive reaction to a new culture. Immigrants can also resist change and resistance to cultural change can occur when the dominant society does not pursue inclusive strategies towards cultural diversity (Berry, 1997). Hence, it is possible that when immigrants do not feel welcomed by the dominant society they will hold onto maintaining their ethnic identity and not pursue adaptation to the dominant culture. 
School culture and climate. A discussion of school culture is relevant to the topic of LTEL students in that the culture of a school impacts the climate of a school. The school climate is the way the school feels to students, teachers, staff, and administrators. A school culture develops as the result of all the interactions of teachers, administrators, support staff, students, school policies, procedures and curricula (Hinde, 2004; Petersen \& Deal, 1998). Through these interactions schools cultivate and communicate their norms and values and "this set of informal expectations and values shapes how people think, feel, and act in schools" (Petersen \& Deal, 1998, p. 28).

For the purpose of this study school culture will refer to school interactions, school policies, assumptions about what students and school should be like, how welcoming the school environment feels to Latino LTEL students, school rules and practices, values expressed in the curricula and classroom teaching, and the decorations displayed in the halls are all parts of school culture (Hinde, 2004). A school's culture can be supportive or constraining to Latino LTEL students.

\section{Background and History}

Traditionally, in the US, the role of schools - in the lives of immigrant studentswas akin to the melting-pot theory, where ethnic minority students would be assimilated to the culture of white, middle class citizens (Berry, 2005; England, 1982; Portes, 1997; Van Oudenhoven, Ward \& Masgoret, 2006). It has long been assumed that immigrants to the US, as part of their integration into their new country, would let go of their ethnic 
identity, culture, and language and fully embrace new identities as Americans. In this melting-pot paradigm of language and culture acquisition, schools expect immigrant students to do all the work to adapt and adjust to the dominant culture of the school. Maintaining this view of ethnic acculturation can inhibit a school's ability to adapt to and incorporate the culture of their ethnic minority students, or engage in what is commonly referred to as acculturation. As our society becomes increasingly multicultural - it is estimated that by 2020 over 40 percent of all students will be ethnic minority studentsschools have a duty to include, and acculturate students of color into their daily narratives and communities of learning (Collier, 1995; Darling-Hammond, 2006; Delpit, 1995; Faltis \& Coulter 2008; US Dept. of Education, National Center for Education Statistics, 2010). Research indicates it is important to understand how students perceive their experiences, thus schools can be made aware of student perceptions and more effectively respond to their student's affective and acculturative needs.

\section{Justification}

Throughout the US, the mechanism for schools to integrate their English learners is through federally mandated and supported English Language Development programs. Schools across the nation are providing ELD classes, as has been required by federal law since Lau vs. Nichols, 1974. The federal statutes that govern state English Language Development (ELD) programs stipulate that equal access for language minority students doesn't mean just providing access to school; the statutes call for providing access for all 
students to participate in a school's programs. "There is no equality of treatment merely by providing students with the same facilities, textbooks, teachers, and curriculum; for students who do not understand English are effectively fore closed from any meaningful education" (US Dept. of Education: Office of Civil Rights, 2012, para 8). Title VI of the Civil Rights Act of 1964 directs school districts to take steps to help EL students overcome language barriers and to ensure that they can meaningfully participate in the districts' educational programs (US Office of Civil Rights, 2012). However, it could be argued that LTELs throughout the US are not being provided an equal access to an education given their insufficient academic English proficiency after 7-10 years in ELD programs (Cummins, 2000; Darling-Hammond, 2006; Faltis \& Coulter, 2008).

LTEL students are not developing the same level of academic English language proficiency as their native English- speaking peers by the senior high school level, and as such, may be graduating from high school unprepared for college - if they graduate high school at all (Faltis \& Coulter, 2008; Olsen, 2010). Throughout the US, ELs have a higher dropout rate than non-ELs. This higher dropout rate also includes students in the census category of linguistic minority students - those who speak another language at home whether or not they are in EL programs. It is projected that by the year 2030 the total EL population - comprising a variety of ethnicities, not just Latinos-- in US schools will exceed 40 percent (US Dept. of Education, 2012).

LTEL students represent a variety of ethnicities and language groups, but the focus of my research will be LTEL students who identify as Latino. It is important to 
make clear that not all students of Latino descent are ELs. A pan-ethnic term like Latino is based upon grouping all the Spanish speaking countries of the Americas into one category, and in such a broad categorization it is easy to lose sight that the term embraces as many cultural differences as similarities (Gutierrez \& Orellana, 2006). There are also many US born students who identify as Latino but do not speak Spanish; additionally, there are Latino families in the Southwest whose US lineage predates US statehood.

\section{Focus of Research}

The high dropout rate and large population of Latino students who enter college unprepared to deal with the rigor of academic English suggest that schools need to do more to help Latino students acculturate academically (Faltis \& Coulter, 2008; Harklau, 2003; Goldschmidt \& Miller, 2005). Because of my concerns regarding the academic and affective learning needs of this population of LTEL students, this study will seek to understand the issue from the perspective of Latino LTEL students. What do the research participants who were Latino LTEL when they were in high school have to say about how schools met or didn't meet their affective learning needs? What do the research participants have to say about how schools may effectively and proactively assisted their affective learning needs of Latino LTEL students in order to support their academic success?

In school districts throughout the country, researchers, educational leaders, parents and teachers are noticing that a majority of students who are not passing state 
reading, writing, or math-standardized tests are from lower income households and/ or are ethnic minority students ( Darling-Hammond, 2006; Faltis \& Coulter, 2008). Nationwide schools are focusing their efforts on refiguring their curricula and instructional practices in order to address this issue (Faltis \& Coulter, 2008; Olsen, 2010; Zen, 2001). In this research, I seek to examine another side of the issue- the role of school culture and school climate as related to the academic acculturation and success of Latino LTEL. To this end, this research endeavors to give authority to student voices and perspectives, as efforts at reforming educational outcomes for Latino EL, "will be based on an incomplete picture of life in classrooms and schools, and how that life could be improved, if we do not include their perspectives" (Cook-Sather, 2002, p. 4). By listening to what former Latino LTEL students have to say about their education experiences, we can better understand how schools can better serve future LTEL's affective and acculturative needs.

\section{Research questions}

The purpose of this study was to describe and explain recently graduated Latino LTEL's perceptions of the impact of their school's culture on their academic and affective acculturation. Through understanding these needs, educators can address the affective learning needs of Latino LTEL within the culture of the schools they attend, and thereby more ably assist Latino LTEL learners to successfully acculturate. In seeking to 
understand how best to support the affective learning needs of Latino LTEL the following questions emerge:

1. What are recently graduated Latino LTEL perspectives of how their high school supported or did not support their academic acculturation while in high school?

2. What are recently graduated Latino LTEL perspectives of how their high school supported or did not support their affective learning needs?

Through interviewing young Latino adults who have graduated from high school within the past 1-3 years and who were identified as Latino LTEL while they were in school, this study may point to ways schools may more effectively address the affective learning needs and the acculturative process of Latino LTEL.

\section{Summary}

Latino LTELs are one of the fastest growing student populations in high schools in the US. In the last 20 years, from nationwide test, it has become apparent that many EL are not exiting ELD programs and/or developing sufficient English language proficiency to be successful academically. Prior research has examined the issue from a programmatic and curriculum perspective, but there is little research that looks at the issue of LTEL from the perspectives of students who have been labeled LTEL. Nor has there been sufficient research as to how school culture may impact the academic acculturation of Latino LTEL. 
The next chapter is a literature review that first examines the metaphors that we use when we discuss the learning of language. Following this discussion is a look at the research that has examined the culture of schools and its impact on ethnic minority students' affective needs as well as a discussion of affective needs and academic acculturation. 


\section{Chapter 2}

\section{Literature Review}

The purpose of this study was to describe and explain recently graduated Latino Long-term English learners' perceptions of the impact of their school's culture on their academic and affective acculturation. Throughout the US, 59 percent of high school English learners are still in ELD programs after 7-10. The majority of these students are Latinos (Goldschmidt\& Miller 2005; Hakuta, 2000; Harklau, 2003; Olsen, 2010). This literature review will summarize key research-based theories regarding English Learners (EL) school culture. Researchers discussed herein submit that schools need to address the complexities of integrating cultural heterogeneity to enable ethnic minority students to feel part of a community and facilitate ethnic minority students access to participation in the larger school culture (Collier, 1995; Delpit, 1995; Darling-Hammond, 2006; Deters, 2011; Faltis \& Coulter, 2008; Gitlin, Buendid, Crossland, \& Doumbua, 2003; Lalas \&Valle, 2007; McLaren, 2003; Roland, 2008; Schumann, 1986; van den Bergh, \& Jiang, 1998).

To develop an understanding of the socio-cultural factors that may lead to students being classified as LTEL, I will draw on prior theory and research. However, I feel it is also important for me to situate myself and my prior experience and knowledge, as my experiences in the classroom inform my research interests. For the past fourteen years I have been a secondary classroom teacher, and for 9 of those years I have taught 
EL students in a suburban school district in the Pacific Northwest that includes swaths of rural zones in its area of attendance. As a teacher, I participated in and observed the inferences, interactions, and perceptions of school staff, administrators with Latino EL. My eight years of experience as a teacher of Latino LTEL is a base from which I started my research.

As Maxwell (2005) discusses, theory is a spotlight that we use to illuminate an issue to help us understand more clearly what is going on. Teachers, like researchers, inductively develop theories to help us understand what is going on in their classrooms and schools, and like researchers, are in "constant interaction with the data" (Maxwell, p 42). My interest in the affective needs of students and the role of school culture and its impact on Latino LTELs' academic English proficiency developed from more than nine years of participation and observation of student, teacher, administrative and support staff interactions with Latino LTEL students.

This literature review explores prior theory and research on Latino LTEL. The first section starts with a discussion of metaphors in relation to learning theories. Through analyzing the metaphors we use when discussing theories of learning we can glean insight into the assumptions being made about an educational issue (Sfard, 1998). For example, what educators assume is true about student learning, and, how they view English learners, impacts how they approach education in practice. Using the metaphors of participation and acquisition, I will discuss how acquiring a language provides a pathway for students' participation in the school culture and participation in the wider 
society. The next section looks at the process of dual acculturation, including the theory that the role of schools is to meaningfully adapt their culture to serve their bicultural students' acculturation and academic success. The last section of this chapter reflects on my choice of theoretical frameworks, which was informed by my teaching experience.

\section{Language Learning and Metaphors}

Sfard (1998) explicates that metaphors are useful tools of analysis in that they can help us understand the underpinnings of a learning theory; our assumptions about learning; and how theories can construct our understanding of learning. She posits that the metaphors teachers use to discuss pedagogy can perpetuate the ways we approach and think about teaching and learning. Sfard focused on two metaphors of learning, acquisition and participation. Acquisition represents learning as the process of knowing and acquiring knowledge as an individual, and as a metaphor indicates that there is an endpoint to the process of acquiring knowledge. Participation represents "the ability to communicate in the language of the community and act according to its particular norms" (Sfard, p.6). As a metaphor, it suggests learning is an ongoing collaborative process of becoming part of a community, Even though Sfard discusses the two metaphors as antonyms of each other, she concludes by saying that they are not mutually exclusive, and that learning involves both acquiring knowledge and using that knowledge as a means to participate in the wider culture. 
Both acquisition and participation as metaphors for learning are relevant in analyzing pedagogical approaches to addressing the affective learning needs of Latino LTELs. Latino LTELs do need to acquire proficient academic English language skills so they can proficiently participate in the culture of academic learning. In addition, acquiring English skills enables Latino LTELs to participate in the dominant culture of their school as well as participate in creating their school's culture. Participation allows them to practice academic and cultural proficiency. The acquisition metaphor suggests that learning is a process of acquiring information and assimilating it for the learner's individual benefit. Acquiring knowledge through education is perceived as a way to acquire access to social power (Collier, 1995; Delpit, 1995; Friere, 1970).

The acquisition metaphor is useful as a rationale for considering ELD programs. ELs need to acquire language skills for academic proficiency. The participation paradigm, however, takes the affective and academic needs of Latino LTEL a step further. The participation metaphor posits that students learn in order to participate in the school culture and society as a whole. Just learning English isn't enough. Latino LTEL need to be able to acculturate to society's social and professional norms of communication, which provide them with the ability to participate (Lave, 1996; Sfard, 1998).

Many ELD programs focus primarily on the acquisition of English language, which seems to put the entire onus for understanding and learning cultural norms on the student. Yet, some researchers of language acquisition strongly suggest that language 
learners learn a second language quicker when they feel safe and comfortable in their learning environment. Krashen's Affective Filter hypothesis indicates that when language learners feel stressed their affective filters are raised; hence, language acquisition will be difficult. Other researchers too have found considering affective needs relevant when considering the in-school learning experiences of LTEL. As Milner (2002) discusses in his study of high achieving African American youth, the social experiences and interests at school of students from diverse cultural backgrounds' may be quite different than their Anglo-American peers. Learning is not just a cerebral experience taking place in the head of the student; rather, learning is a socio-cultural process, based in relationships (Booker, 2007; Collier, 1995; Cummins, 2000; Krashen 1982; Lavadenz, 2010). Prior Research indicates positive school affect; such as a sense of belonging, feeling valued and cared for; positively impacts students' motivation, engagement and achievement (Chhoun, \& Wallace, 2014; Combs, 1982; Faircloth, 2009; Faircloth \& Hamm, 2005; Milner 2002; Osterman, 2000).

Collier too sees students' affective needs a factor that impacts EL's language development. Collier's Language Acquisition for School model of language learning refers to these affective needs as social and cultural processes that can impact a student's response to learning (Collier, 1995). Collier includes student self-esteem and motivation as elements of student's affective needs. If educators only focus on the acquisition of language skills, they may lose sight of students' affective learning needs and what theory suggests we need in order to facilitate low stress learning environments. 
Students in ELD programs are studying English so they can access an education and academic English which affords them the opportunity to successfully participate and be successful in society's mainstream culture. In general, the literature that examines the issues related to Latino LTEL focuses on the programs themselves rather than the students, emphasizing the deficits of ELD programs (Faltis \& Coulter. 2008; Forrest, 2006; Goldschmidt \& Miller, 2005; Zen, 2001). The main critiques claim that ELD programs lack academic rigor, do not prepare students for college; do not provide enough opportunities for interaction with mainstream students, and lack bi-lingual literacy programs (Forrest, 2006; Goldschmidt \& Miller, 2005; Olson 2010; Zen, 2001). However, what might be missing from these critiques of ELD programs is a focus on the ways in which the programs frame language learning. The types of deficits identified in ELD programs align with an acquisition (or rather a non-acquisition) metaphor in that often, in my experience, ELD teachers speak about students acquiring or not acquiring a language. I would argue that a focus on acquisition obscures students' need to feel part of their schools, the need to be able to meaningfully participate in defining their school culture, and their need to feel comfortable using academic language. When students are not at ease navigating their school's cultural norms, their affective filter is likely to be high, which impedes language acquisition (Faircloth, 2009; Faircloth \& Hamm, 2005; Osterman, 2000). 


\section{Dual Acculturation}

The role of the dominant culture and educational institutions in EL students' learning and acculturation is relevant in seeking to understand the needs of Latino LTELs. Many researchers posit that education in the US is based on tacit cultural understandings that are not usually made explicit to immigrants and children of immigrants (Donato \& MacCormick, 1994; Friere, 1970; McLaren, 2003; Norton \& Toohey, 2001; Schumann, 1986). However, as noted, acculturation is a two way street, and as such, schools also need to acculturate and adapt to their diversifying student populations. It seems there is much agreement that what many Latino LTEL need is assistance in acculturating, or, as Lave (1996) would say, they need to be welcomed into communities of learning (Gitlin et al., 2003; Spencer, 1999; Whitlock, 2006).

Education conveys shared cultural values that are inculcated through schooling (Donato \& MacCormick, 1994; Lantoff, 1994; Marshall \& Gerstl-Pepin, 2005; Fowler, 2004; Norton \& Toohey, 2001; Tyler et al., 2008). Researchers suggest that schools would benefit students by: taking proactive steps to integrate culturally diverse students; and seeking to understand the ways Latino LTEL perceive and interpret their relationships with mainstream teachers and peers (Cummins, 2000; Gibson, 1997; Li, 2010; Roland, 2008; Spencer, 1999; Whitlock, 2006). Such practices would help schools to proficiently adapt and acculturate to a diversifying student body (Berry, 2005; Gibson, 1997; Li, 2010). 
Educators can ameliorate inequitable educational outcomes experienced by Latino LTEL students not only by attending to their students' literacy needs, but also, by teaching Latino LTEL how to navigate cultural relations and differences. Such practices may engender their participation in the school's learning community (Delpit, 1995; Collier, 1995; Cummins, 2000; Lave, 1996; McLaren, 2003; Osterman, 2000; Peguero, 2010; Roland, 2008).

Osterman, in her review of research that studied the interface between school practices and performance of students in school, discusses how the sense of belonging to a community is a fundamental need (2000). A student's sense of belonging is developed through their reciprocal interactions and relationships with teachers and other students. According to Osterman, the research across fields prevailingly link a sense of belonging and feeling part of a community with increased academic engagement and positive academic attitudes. Likewise, an absence of a sense of belonging and involvement can lead to decreases in academic performance and engagement (Booker, 2007; Faircloth \& Hamm, 2005; Lopez, 2010; Osterman, 2000; Whitlock, 2006).

Latino LTEL students need to learn how to access mainstream cultural relations and authority in order to get their academic and affective needs met (Collier, 1995; Cummins, 2000; Delpit, 1995; Faltis \& Coulter, 2008; Lopez, 2010; Valdes, 2001). Schools, like all institutions, have their own intercultural dynamics that are not always obvious to students, especially EL students (Marshall \& Gerstl-Pepin, 2005). An important aspect of meeting the affective needs of EL students is providing them with 
opportunities to participate in the school's broader community and culture (Delpit, 1995; Collier, 1995; Cummins, 2000; McLaren, 2003). However, the case for many students is that if they are not shown how to navigate school culture and aren't explicitly invited to participate, they don't learn how (Dalton \& Sison, 1995; Delpit, 1995; Faltis \& Coulter, 2008; Lave, 1996; Valdes, 2001; Valenzuela, 1999). Schools must welcome ethnic minority students, and help them to navigate a new culture in order to facilitate dual acculturation. Immigration and learning theories articulate that not only do students need to acculturate, but that schools also need to acculturate and adapt to the changing demographics of their student population (Berry, 1997; Brown et al., 1989; Ernst, 1997; Roland, 2008).

\section{Student and School Perceptions}

As a teacher, when I attended in-service staff meetings that touched on issues of diversity and Latino achievement gaps, there was always discussion of what we need to do to for them, but little to no discussion of our school's culture, or of the ways ethnic minority students were perceived and welcomed by students, teachers, staff and administrators. Most LTEL academic interventions focus on student academic deficiencies, and only rarely are challenges analyzed from the perspective that a schools' culture may also need to adapt and acculturate to their changing student demographics (Collier, 1995; Collier \& Thomas, 1989; Delpit, 1995; Faltis \& Coulter, 2008; Lalas \& Valle, 2007; Spenader, 2011). When our schools ignore their English learner's complex 
bi-cultural identities, students can end up not feeling a part of the school, which may be one reason why ethnic minority students and students of color or poverty continue to have higher dropout rates and lower rates of college attendance (Booker, 2007; DarlingHammond, 2006; Faltis \& Coulter, 2008; Fowler, 2004). School administrators often focus on Latino LTEL deficits as the problem and not the school's deficit of cultural competencies (Delpit, 1995; Faltis \& Coulter, 2008).

There is significant research that investigates how school culture impacts the way students perceive themselves and their place in the hierarchy of school culture (Aranson, 2004; Booker, 2007; Gitlin et al, 2003; Steele \& Aronson, 1995; van den Bergh \& Jiang 1998). Aronson (2004) conducted a study to research how a school's pre-conceived notions of students' ethnicity can impact students' perception of themselves and their academic achievement. His research suggests that negative stereotypes of ethnic minority students "makes students anxious which can suppress their performance" (Aronson, 2004, p 20). Van den Bergh \& Jiang came to a similar conclusion in their study regarding whether the prejudiced attitudes of teachers could explain "differing ethnic achievement gap sizes across classrooms via teacher expectations" (van den Bergh \& Jiang, 1998, p. 516). Both studies found a significant relationship between teacher's stereotypes of their ethnic minority students and ethnic minority student's academic achievement (van den Bergh \& Jiang, 2004).

Gitlin et al., (2003) in their study of a middle school ESL program and the school community's attitudes toward these immigrant youth concluded that stereotypical 
attitudes toward ethnic minority youth can "limit opportunities for immigrant students and place them at the margins of a school's culture" (p. 91). Their study of middle school ESL children reveals that how ethnic minority students are regarded often places them on the margins. The school's discourse, policies and practices towards its ESL population-even though it had multi-lingual signs throughout the building welcoming students, "excluded them culturally, physically and socially from the inherent benefits of residing at the center" (Gitlin, et al., p. 244 ). Hence, when EL students' culture or their experience of reality aren't represented in their schools' culture, students may interpret this omission as not being valued members of the school culture (Darling-Hammond, 2006; Delpit, 1995; Lalas \& Valle, 2007; Norton \& Toohey, 2001; Roland, 2008; Valdes, 2001).

\section{Theoretical Framework}

Theories of learning help us to understand the learning process; by understanding how learning occurs we can more effectively facilitate student learning. Theoretical frameworks are useful mental models and metaphors. They provide us with common vocabularies and models for understanding school dynamics. When we need to understand why an organization, such as a school, is not getting the results it expected of its efforts, theoretical frameworks can help us navigate an understanding of the issues, analyze problems, and propose solutions (Bolman \& Deal, 2008). Educational theories provide lenses through which we can analyze underlying relationships through such 
things as school structures, school communication, problem solving approaches and problem solving abilities. In the following section, I will discuss two theoretical frameworks, socio-cultural theory and critical pedagogy and how they apply to the issue of academic language proficiency of LTELs.

Analyzing possibilities and solutions for addressing the impact of school culture on the academic success of Latino LTEL from socio-cultural and critical pedagogy frameworks is appropriate, as socio-cultural perspectives view learning as being collectively and socially constructed. Critical pedagogy examines how schools can perpetuate or transform inequitable educational outcomes. These two theoretical frameworks provide insights about how to facilitate the equitable construction of knowledge for ethnic minority students. In the following section, I will further explore how various constructivist theories provide viable theoretical tools for analyzing the role of affective needs in learning. Finally, I will discuss perspectives of critical pedagogy as a means to understand the importance of equitably acculturating a school's culture to serve the learning needs of LTEL, and their integration into school culture.

Socio-Cultural Theory. Constructivist socio-cultural theory is an apt lens from which to analyze the effect of the culture and climate of schools on LTELs academic development. Socio-cultural theory is based upon the work of Lev Vygotsky (1962). Vygotsky built his theory upon constructivism, which sees learning as situated and influenced by social and cultural factors. As a theory of learning and knowledge, 
constructivist socio-cultural based theories view knowledge as contextually constructed and socially and culturally mediated (Brown et al., 1989; Fosnot, 1996; Lave, 1996; Norton \& Toohey, 2001; Wenger, 1998). In other words determining: what information is important to know, how to understand that information, and how you demonstrate that learning, is based upon the values of the milieu (Lave, 1996). Language, meaning, and educational values are societally constructed over space-time and are culturally specific. This points to why bi-cultural students' opportunities to acculturate may be limited unless their acculturation is mediated and scaffolded (Donato \& MacCormick, 1994; Fosnot, 1996; Lave, 1996; Lavendenz, 2010; Norton \& Toohey, 2001; Vygotsky, 1962).

For socio-cultural theorists, social interaction is seen as the basis of learning and academic development (Brown et al., 2011; Vygotsky, 1962; Wenger, 1998). Humans are in a dynamic state of learning as they respond to their environment and the environment responds to their learning. Schools are not just places where students are recipients of culturally relevant information; students are also learning how to interact in the social sphere away from home and learning what knowledge is important to our society (Lave, 1996; Norton \&Toohey, 2001; Vagan, 2011; Wenger, 1998). These school-based interactions impact students' identities as learners and their identities as learners matter because they provide a basis for what they think is possible for themselves as students and as adults (Booker, 2007; Oyserman \& Destin, 2010).

Often, educators and educational leaders operate from the premise that knowledge is a process of transference from the teacher to the student, enacting what Friere (1970) 
referred to as" banking education". This view, where students are seen as passive recipients of information, ignores a major premise of socio-cultural theory: that knowledge is situated, "a product of the activity, context, and culture in which it is developed and used" (Brown et al., 1989, p. 32). In other words, knowledge is not selfevident; rather, "it is a function of the culture and the activities in which the concept has been developed" (Brown et al., p. 33). This suggests that what is considered knowledge and important to learn may be invisible to LTEL students from cultures other than the dominant culture of the US. It is entirely possible for LTELs to be successful in certain performances in school, but they still may not be participating in the overall school culture. For example, ELs may pass standardized tests "but still not be able to use a domain's conceptual tools in authentic practice” (Brown et al., p. 34). This harkens back to the metaphors of acquisition and participation, in that students need opportunities and explicit invitations to participate in the school culture so they may apply their academic English language proficiency.

A socio-cultural approach to understanding learning processes addresses the importance of students (all students, but importantly to this research, Latino LTELs) learning how to become part of a school culture, in that doing so teaches students how to navigate and participate in the culture of the wider society (Cummins, 2000; Faltis \& Coulter 2008; Lave, 1996; Roland, 2008). In the daily negotiation of school halls, lunchrooms and classes, students develop their self-identity in relation to society. The metaphor often used to describe socio-cultural constructivism is "people in conversation" 
(Ernst, 1997). Underpinning socio-cultural lenses is the recognition that it is through language that knowledge and meaning are socially negotiated (Deters, 2011; Ernst, 1997; Lave, 1996). Social constructivism views humans as formed though their interactions with each other; i.e. our view of the world and ourselves is socially constructed through our interactions with others (Lave, 1996, Wenger, 1998). According to socio-cultural theory student identity is also constructed through their interactions at school and in daily life (Deters, 2011; Lave, 1996; Norton and Toohey, 2001; Roland, 2008; Valdes, 2001; Wenger, 1998). Hence, we need to provide meaningful and scaffolded opportunities for Latino LTEL to interact and participate in the broader culture. This theoretical framework points to ways to facilitate acculturation of LTELs, which is another reason why it is a relevant theoretical framework for examining the issue of school culture and its impact on the development of LTELs academic proficiency.

Socio-cultural theorists, such as Lave (1996), recognize that educational institutions are mini-cultures within themselves where students learn to relate to the larger community (Ernst, 1997; Faltis \& Coulter, 2008; Roland, 2008; Vagan, 2011). As people engage in communities of practice they also construct identities in relation to the communities (Deters, 2011; Lave, 1996: Wenger, 1998). The ways in which LTELs end up navigating their school experiences can impact how they construct their identities as learners and participators in the wider culture (Darling-Hammond, 2006; Delpit, 1995; Deters, 2011; Norton \& Toohey, 2001). For some Latino LTEL students, the school environment is the only place in their daily lives where they have sustained interaction 
with the mainstream culture (Delpit, 1995; Faltis \& Coulter, 2008; Li, 2010). Sociocultural theorists sometimes compare schools to an apprenticeship, where all students are being acculturated into ways of talking, thinking, believing, and acting that are recognized and valued in our society (Brown et al, 1989; Faltis \& Coulter, 2008; Lave, 1996; Wenger, 1998). Students' perceptions of themselves as part of a school, society, and as learners are shaped by their experiences at school, Latino LTEL pick up cues of how and where they fit in from their interactions with teachers and other students (Delpit, 1995; Gitlin, Buendid, Crossland, \& Doumbua, 2003; Lave, 1996; Roland, 2008; Wegner 1998).

Some socio-culturally informed researchers discuss the notion of "figured worlds", this idea explains that an individuals' identity, their sense of themselves, emerges from and is shaped through their interactions within particular social contexts (Li, 2010; Rubin, 2007; Urrieta, 2007). Urrieta,(2007) explains that identity formation in relation to figured worlds is "about how people come to understand themselves, how they come to figure who they are, through the worlds that they participate in and how they relate to others within and outside of these worlds" (p. 107). Through daily participation in school, Latino LTEL students encounter views of their home culture and ethnicity that frame them as certain types of learners. Rubin (2007) explains that over time how others view LTEL students will impact their "success and persistence" (p. 223), she also suggests that students' self-identities as learners can become fossilized through years of classroom interactions. 
Facilitating bicultural students' acculturation to a school's community of practice also teaches students how to navigate and participate in the culture of the wider society (Cummins, 2000; Delpit, 1995; Faltis \& Coulter, 2008; Peguero, 2010). Research clearly indicates that there is a connection between positive self-identity and acculturation; however, learning a second language is just one aspect of the process of acculturation. The degree to which a language learner acculturates impacts their level of second language acquisition (Shaumann, 1986). When LTEL students can't figure out the school culture and an ELD program doesn't explicitly teach that level of acculturation, students are often left feeling alienated (Faltis \& Coulter, 2008; Lavedenz, 2010; Peguero, 2010). There is a significant body of current socio-cultural based research that indicates that a sense of belonging enhances and supports academic achievement. Conversely a lack of connection to school and teachers adversely impacts students attitudes and their motivation to succeed academically (Booker, 2007; Chhuon, \& Wallace, 2014; Faircloth, 2009; Li, 2010; Osterman, 2000; Oyserman, \& Destin, 2010; Usher \& Kober, 2012).Once students feel alienated they are less likely to take their school studies seriously and can potentially develop oppositional behaviors that can impede their learning (Booker, 2007; Delpit, 1995; Faltis \& Coulter 2008; Usher \& Kober, 2012). If it is assumed that a sense of belonging is a necessary affective component for student motivation, then educators need to look at ways they can include the growing cultural diversity that schools across the nation are experiencing. Socio-cultural theory and constructivism makes it clear that learning is a social process, and if students are not explicitly invited, welcomed, and 
apprenticed into our communities and cultures of learning, they won't feel part of the school culture, nor of the wider culture (Delpit, 1995; Lave, 1996; Norton \& Toohey, 2001; Wegner, 1998).

Schools can promote Latino LTEL positive identity as learners by facilitating their participation and interaction within the school culture (Giang, \& Wittig, 2006; Jimenez, 2000; Valenzuela, 1999; Whitlock, 2006). Teachers and administrators can craft school social structures that consciously help the entire school community address the complexity of navigating cultural differences, help ethnic minority students feel part of a community, and facilitate ethnic minority students contributions to the larger community (Brown, Collins, \& Duguid, 1989; Delpit, 1995; Peguero, 2010; Roland, 2008; Shumann,1986).

Critical Pedagogy. When considering the varying ways Latino LTEL may become acculturated into a school's culture, issues of equity may emerge. Thus, critical theory may be useful in exploring these tensions, as it is a framework for analyzing societal and institutional power relations (Friere, 1970; McLaren, 2003). Critical theory challenges educators to examine assumptions about power relations (Friere, 1970; McLaren, 2003). Critical theorists ask and analyze who has power, what are they doing with it, and who benefits from it. With regard to the affective learning needs of Latino LTEL in school, critical theory provides a framework for promoting social equity (Booker, 2007; Cummins, 2000; Faircloth, 2009; Faltis \& Coulter, 2008; Friere, 1970; 
Gibson, 1997). This theoretical framework explicates that schools, as public institutions, support a particular view of what knowledge is and what is important to know. For example, the academic discourse in textbooks and curricula represents ethnic minority students' cultures as unequal, and critical theory explains that this is one way that schools (perhaps unwittingly) maintain academic inequities (Faltis \& Coulter, 2008; Friere, 1970; Gibson, 1997; McLaren, 2003).

Critical theory posits that schools can promote student empowerment or disempowerment (Faltis \& Coulter, 2008; Gitli et al., 2003; McLaren, 2003). In US schools, the cultural narrative from kindergarten through high-school is one of a whiteprotestant-dominant America, and ethnic minority students are expected to acculturate to the middle-class-dominant culture (Friere, 1970; McLaren, 2003). Critical pedagogy provides a framework for educators to critically analyze the ways in which their schools and curricula prepare students for life in the wider culture. Critical theory puts the onus on teachers and school leaders to transform the subtle features of inequity that permeate LTEL students' everyday classroom experience (Collier, 1995; Cummins, 2000; Delpit, 1995; Friere, 1970; Norton \& Toohey, 2001; McLaren, 2003). This theory also suggests that giving authority to student voice is a way to transform educational inequities (Friere, 1970; Cook-Slather, 2002) As schools look to improve the educational outcome of Latino EL, listening to voices of former LTEL as they share their high school experiences may provide insights into ways to support the affective learning needs, academic success, and acculturation of Latino EL (Cook-Sather, 2002). Pedagogy informed by critical theory 
can guide schools in their attempts to positively acculturate their school culture to welcome and empower Latino LTELs.

\section{Summary}

I chose to focus on the affective needs of Latino LTELs and how school culture impacts those needs, based on my experience as a teacher of LTEL. As a teacher, I have witnessed the unintentional exclusion of Latino and other ethnic minority students in schools. I have worked in schools where Latino students were victims of racism by peers on a daily basis. When these students brought this to the attention of teachers or administrators, the perpetrators were sometimes merely given detention with no opportunities for learning that their behaviors were racial harassment. By not considering the role of school culture on bicultural students' academic acculturation, and identity as learners, schools can send an unintended and disempowering message of exclusion.

Even though much of the literature on the education of ethnically diverse students recognizes that integration and acculturation into school culture is a vital aspect of ethnic minority students' academic success, the approach to integrating language minority students often focuses solely on their acquisition of language and knowledge (Collier, 1995; Cummins, 2000). However, acquisition, as a concept and metaphor in referring to the language learning process, seems one-dimensional, implying that education is a oneway process. Acquisition doesn't address the social and situated nature of language learning. Classroom knowledge and school knowledge have certain assumptions 
embedded within them that are often not made explicit to ethnic minority students (Delpit, 1995; Rubin, 2007; Valdes, 2001; Valenzuela, 1999). As educators, we need to be conscious of the school as a cultural terrain where students are forming self-identities in relation to others (Delpit, 1995; Lave, 1996; McLaren, 2003; Wenger, 1998). It is possible that by sticking to metaphors that focus on acquisition of learning, rather than the metaphor of participation in the broader culture, schools and ELD programs are not taking steps needed to assist students in developing skills to adapt to the school's culture and hence limiting their opportunities to participate. Schools, in order to facilitate the successful academic integration of their EL students, also need to acculturate and consciously choose to welcome ethnically diverse students into their learning communities. Socio-cultural theory and critical theory suggest it is possible, through consciously crafting inclusive spaces and narratives within classrooms and school organizations to meet the affective learning needs of ethnic minority students, we can positively impact the English academic proficiency of these students.

In the next chapter, Methods and Procedures, I describe the qualitative research methods, the data gathering process, and the research participants and how they were chosen and the coding process I utilized for data analysis. Finally, I explain the methods used to ensure research validity and participant confidentiality. 


\section{Chapter 3}

\section{Methods and Procedures}

This chapter will present an in-depth explanation of the qualitative methods and procedures used to conduct this research and analysis. The purpose of this study was to describe and explain recently graduated Latino Long-term English learners' perceptions of the impact of their school's culture on their academic and acculturation. By giving voice to the educational experiences of Latino EL we can learn from their perspectives and potentially improve our pedagogical practices and our EL students' academic outcome.

\section{A Qualitative Approach}

Qualitative research seeks to understand social phenomena from the perspective and experiences of the participants (Merriam, 2009). As I am interested in understanding the lived school experiences of Latino LTELs, how they make sense of their school experiences, and the role of school culture in impacting their academic acculturation, I

conducted a qualitative research study (Maxwell, 2005). Through analyzing the personal narratives derived from the interviews of recent high school graduates who were classified as Latino LTEL, understanding of the critical affective learning needs of Latino LTELs may evolve. Qualitative research is the approach called for when researchers want 
to "understand how people interpret their experiences, how they construct their worlds, and what meaning they attribute to their experiences" (Merriam, p. 5).

There are many sociocultural complexities that influence the development of academic English language proficiency. Complex sociocultural issues like language development are not easily solved just through the application of new curricula or ELD techniques (Collier, 1995; Lavadenz, 2010; Lavadenz Armas, \& Barajas, 2012; Valdes, 2001). It is my experience, as a teacher, that student learning is impacted by their relationships to their teachers, other students, and the school environment. Recent Latino LTEL have insights about their experiences that would not be apparent to those who are not of an immigrant-minority background. These interviews with recently graduated Latino LTEL, can potentially help us understand the ways in which Latino LTEL felt constrained or supported in their academic acculturation. I also sought participant's suggestions and ideas of how educators may more ably support Latino LTEL to successfully acculturate to school. The following are the questions that guided my research:

1. What are recently graduated Latino LTEL perspectives of how their high school supported or did not support their academic acculturation while in high school?

2. What are recently graduated Latino LTEL perspectives of how their high school supported or did not support their affective learning needs? 


\section{Data Gathering}

Research underpinned by a sociocultural and critical pedagogical perspective suggests that listening to the schooling experiences of Latino students "has the potential to enhance understandings, and subsequently strengthen practice, by illuminating the dominant discourses that undergird both" (Hungerford-Kresser \& Vetter, 2012, p. 223). Listening to the lived experiences of Latino LTEL has the potential to provide insights that go beyond the current dialogue in academia on the deficit of ELD programs, and impel us to examine the role of school culture and how it impacts the affective and academic learning needs of Latino LTEL (Cook-Sather, 2002).

Socio-cultural and critical theory inform us that our perceptions of reality are built through experience and interactions; hence our experience of reality is relative. This ontological stance, or what we assume we can know about the world, does not mean that a qualitative study is not generalizable beyond the particular participants (Maxwell, 2005). Ostensibly, qualitative studies can provide doorways of understanding into the perspectives of particular populations of individuals. Those insights can lead to the development of a theory that can be extended to similar situations (Maxwell, 2005).

This qualitative study employed the following data gathering approaches: a demographic questionnaire for gathering baseline background information about the participants, and hour-long semi-structured one-to-one interviews with 10 students where, using a questionnaire as a guideline, Appendix B, we discussed their high school 
social and academic experiences. Through an analysis of the interviews we may come away with deeper understandings of the complex acculturation process that bi-cultural students undergo. It is also my hope that this study provides understandings of the sociocultural processes involved in bi-cultural students' learning from a Latino LTEL student's perspective.

Demographic questionnaires. Participants filled out the questionnaire after they filled out the IRB form and before the interview started. The purpose of the questionnaire was to have demographic data to compare the students' backgrounds, the number of years in ELD programs, and to ascertain whether participants received formal education in their first language. Background knowledge of this type helps to establish whether students were indeed Latino LTEL in high school and determine if the participants have other demographic commonalities that may be relevant, such as parent's education, country of origin, when they first started English. This socioeconomic data helps to determine the degrees of acculturation the students may have had to master in order to participate in their school's culture (Collier, 1995).

Interviews. Interviews provide an opportunity to gather a lot of information about a participants experience in a relatively short period of time (Merriam, 2009). The one-on-one interviews conducted for this study offer data that is "detailed enough that they provide a full and revealing picture" of Latino LTEL perspectives on what it is like to be EL students (Maxwell, 2005, p. 244). All the interviewees had first-hand knowledge and insights to share about their educational experiences as Latino LTEL. As will be 
discussed in chapter 5, these interviews provided some insights as to how we can practically and more effectively meet the affective and academic learning needs of Latino LTEL.

Pilot Study. One of the young women I initially contacted volunteered to be my pilot study interviewee. The goal was to ascertain whether my questions were viable, whether they would elicit the data needed in order to answer to my research questions. I put together a series of questions and it quickly became clear that my questions were too elusive. From the desire to not lead or coach the participant my initial questions were not specific enough. The pilot interview helped me to see that I needed to revise my questions. To revise my interview questions, I worked with one of the professors on my committee who has qualitative research experience. She assisted me in crafting questions that pointedly addressed my research questions and were open-ended enough that they allowed for interviewees to convey their unique perspectives as Latino LTEL

Participants. I contacted over 25 former Latino LTEL, who were suggested by teachers and other participants. As I am no longer teaching high school, in order to find participants for the study, I asked high school teachers in my district, they gave me a couple of names of former students whom I then contacted through the social media site facebook, email and/ or phone calls. When they responded I then sent them the "Invitation to participate in a study" letter (see appendix), to ask if they would be willing to participate in this study, 11 students responded. One student became my pilot 
interviewee. Sixteen replied that they would like to participate, and in the end only ten actually participated.

Participants in this study were recent high school graduates who self-identified as Latino and were considered Long-term English learners while in high school. Of the individuals recruited eight attended the same high school in a suburb of Portland.Seven were former students who were in my ELD classes for a year. The ten participants included four males and six females. All participants were between nineteen and twentyone years of age and graduated from high school within the last one to three years. This demographic, high school graduates, was chosen as I wanted the insights of students who had recently graduated high school. It seems to me, that as young adults former Latino LTEL students would have distance from the experience that would enable a mature reflection on their experiences. Additionally one of my interests was whether students felt prepared for college, and having all participants be graduates enabled me to collect data as to whether they had attended college and had felt prepared for college. Even though college attendance wasn't part of my research questions it does give insight as to their academic acculturation. Tables 4 and 5 in chapter 4 provide a tabulated summary of participant demographics.

The fact that the majority of the participants were former students of mine has benefits and potential limitations. Even though I had not been in contact with all but one of them since they were high school, a period of 2-3 years, participants knew me; and I assumed they felt safe having reflective conversations with me because they were willing 
to share personal experiences. A potential drawback is that they may have monitored their responses and may not be as direct as they would with someone who had not been a former teacher of theirs.

A few of the participants are current college students; one has graduated from a Certified Nursing Assistant community college program; one has received her Bachelor's degree; another is working towards an aesthetician license; one started studies at a community college after high school but only finished one term; some are working and are not currently pursuing post-high school education. They each have a story to tell about their high school experiences that provide insight as to how our schools can better facilitate the affective learning needs of Latino LTEL and their academic acculturation.

Interview questions. The interview questions evolved from the research literature, my research questions and objectives, and from the result of the pilot run of my questions. The intent of the questions that were eventually written was to gain insights into whether the participants had felt: supported; like they belonged; had access to support; and comfortable expressing their culture. In all, I asked 14 questions. In Table 3, (see below) the interview questions are correlated to this study's research questions. When designing the questions for the interview I sought to ask questions that would enable me to answer my research questions, and to collect data about students' affective needs. To distill from my research questions those factors that comprised affective needs, I crafted questions that explored whether the participant had experienced: school support for developing academic English, connections to school, a sense of belonging, support for 
academic and social acculturation and whether they felt represented in their school's culture. 
Table 3.

Interview questions and their connection to themes from the research literature

\begin{tabular}{|c|c|c|c|c|}
\hline Interview questions & Belonging & $\begin{array}{l}\text { Academic } \\
\text { acculturation }\end{array}$ & Supported & $\begin{array}{l}\text { Cultural } \\
\text { identity }\end{array}$ \\
\hline $\begin{array}{l}\text { 1. Tell me about a teacher who was } \\
\text { supportive of your academic growth. Give } \\
\text { an example. }\end{array}$ & $\mathrm{x}$ & $\mathrm{x}$ & $\mathrm{x}$ & \\
\hline $\begin{array}{l}\text { 2. Tell me about a teacher who wasn't } \\
\text { supportive of your academic growth. Give } \\
\text { an example. }\end{array}$ & & $\mathrm{x}$ & & \\
\hline 3. How long were you in an ELD program? & & $\mathrm{x}$ & $\mathrm{x}$ & \\
\hline $\begin{array}{l}\text { a. How was the program supportive of your } \\
\text { social growth? Give an example. }\end{array}$ & $\mathrm{x}$ & & $\mathrm{x}$ & $\mathrm{x}$ \\
\hline $\begin{array}{l}\text { b. How was the program supportive of your } \\
\text { academic growth? }\end{array}$ & $\mathrm{x}$ & $\mathrm{x}$ & $\mathrm{x}$ & \\
\hline $\begin{array}{l}\text { c. Explain how you feel it has it helped } \\
\text { you. }\end{array}$ & & $\mathrm{x}$ & $\mathrm{x}$ & $\mathrm{x}$ \\
\hline $\begin{array}{l}\text { d. Explain how you feel it may have } \\
\text { hindered you. }\end{array}$ & & $\mathrm{x}$ & & \\
\hline $\begin{array}{l}\text { b. Did you have friends who were from } \\
\text { other ethnicities? }\end{array}$ & $\mathrm{x}$ & $\mathrm{x}$ & $\mathrm{x}$ & $\mathrm{x}$ \\
\hline $\begin{array}{l}\text { 4. How would you describe your sense of } \\
\text { feeling part of your school? Give an } \\
\text { example. }\end{array}$ & $\mathrm{x}$ & $\mathrm{x}$ & $\mathrm{x}$ & $\mathrm{x}$ \\
\hline $\begin{array}{l}\text { 5. How did being in an ELD program } \\
\text { affect how others viewed you? Give an } \\
\text { example }\end{array}$ & $\mathrm{x}$ & $\mathrm{x}$ & $\mathrm{x}$ & $\mathrm{x}$ \\
\hline $\begin{array}{l}\text { 6. How did being Latino/a affect how other } \\
\text { students viewed you }\end{array}$ & $\mathrm{x}$ & $\mathrm{x}$ & $\mathrm{x}$ & $\mathrm{x}$ \\
\hline $\begin{array}{l}\text { 7. Were adults, at your school (s), } \\
\text { supportive of Latino culture being } \\
\text { expressed at school? Give me an example? }\end{array}$ & $\mathrm{x}$ & $\mathrm{x}$ & $\mathrm{x}$ & $\mathrm{x}$ \\
\hline
\end{tabular}


8. Do you think you were prepared for college after graduating high school?

Explain

9. Did you feel comfortable speaking Spanish at school?

$\mathrm{X}$

$\mathrm{X}$

$\mathrm{X}$ you? What about other Latinos

12. Who at school took time to make sure you knew how to navigate school rules and procedures? Give me an example.

13. How could the high school you attended better serve the needs of their English Language Learners?

14. What would you tell a high school administrator to help them provide a socially and academically supportive environment for their Latino ELL students? $\mathrm{x}$
$\mathrm{X}$

$\mathrm{X}$

$\mathrm{X}$ $\mathrm{x}$

$\mathrm{x}$

$\mathrm{x}$

$\mathrm{x}$ 
wrote notes and asked the interviewee to repeat certain responses. The interviews were semi-structured; I had a list of questions that I asked (see Appendix B and Table 3). These questions guided the topics and issues, but the wording used for each question occasionally changed in response to the participants' answers. A semi-structured interview allowed me as a researcher to respond to "the emerging world view of the respondent and to new ideas on the topic" (Merriam, 2009, p. 90). My goal with the type of questions I used was to allow me to adapt my questions to individual experiences and responses (Krathwohl, 2009). The participants' responses guided any follow up questions and occasionally the sequence of the interview questions.

For transcription of the data, I sent the recorded interviews to be transcribed to Verbalink, a transcription service. The interviews were transcribed verbatim. There were sentences where the transcriber was not able to understand the words spoken, in these instances I re-listened to the interview and filled in what I heard.

\section{Data analysis}

For this particular qualitative research project, interviews and a demographic questionnaire are the basis of data analysis and theory building. As I was collecting data, I used a constant comparison approach to begin understanding and analyzing participants' experiences (Merriam, 2009). I didn't take notes during the interviews, but before sending them to be transcribed I did listen to each interview several times and took notes on themes and similar experiences that were emerging. The transcripts of the 
interviews and the questionnaires were loaded into Atlas t.i., a qualitative analysis software program. I listened to and read through each interview at least five times. The first time I read through the transcript of each interview, I wrote short descriptives, called "free codes" in Atlas ti, of salient parts of the data.

Coding. Saldana (2009) explains that coding is a process of analysis, where one looks for patterns and common ideas, "you use classification reasoning plus your tacit and intuitive senses to determine which data look alike and feel alike when grouping them together" (p. 9). The first cycles of coding attuned me to the perspectives of the participants; I sought to reap their understanding of the relevance of school culture in their academic and educational acculturation. After the first few readings I loaded the transcripts in Atlas ti, a qualitative analysis software program and started ascribing codes to interview passages and quotes. This involved reading the transcript while in Atlas ti, and as I read I wrote down a 1-3 word description of salient responses. As I coded, I looked for commonalities in language, experiences, and world views. I used coding as a way to compare and organize data interpretation among the individual interviews. Atlas ti stores the codes and the quotes that are connected with the code and can provide reports of code lists and their associated data. Once the data was coded I looked for thematic patterns throughout the transcribed interviews (Saldana, 2009).

Before I reread and coded the interviews in Atlas ti, I looked at my research questions, my notes on affective needs, the research literature and decided to code for 
impacts of: belonging, connectedness/ disconnectedness, access to resources, participants feelings about themselves as learners, feeling culturally represented, academic support, and interactions. I chose these types of codes after the initial readings of the interviews, as these topics seemed to be emerging themes across the interviews, as well these codes address some of the descriptions of students' affective needs as described in the research literature. I then employed a descriptive/open coding scheme to classify common themes and patterns of experience across the interviews (Saldana, 2009). As I read and coded I also looked for similarities and differences in participants' narratives, or frequency of certain types of experiences, encounters, views, or opinions (Saldana, 2009). I ended up with over 90 codes.

Code families. The next step in organizing the number of codes I had was to categorize them into thematic categories referred to as code families (Saldana, 2009). Working with a dissertation committee member, Professor Esperanza De La Vega, we organized the codes into 4-5 categories. I printed out an Atlas ti list of the all the codes, and cut out the individual codes. We used five sheets of different colored construction paper and pasted the individual ninety plus 90 codes onto the various sheets of construction paper as they now represented codes with commonalties. The code families were derived through this process; blue sheet became a code family, the green, white etc. We discussed these categories and then loosely named them; the four major code families/themes are as follows: affective needs, acculturation, identity, and academic support. Appendix E contains the code families that the codes were assigned to, the 
definition or rational of the code family and a list of the codes that make up the code family, also indicated is the number of participant quotations associated with the codes.

\section{Researcher subjectivity and validity}

My interest and approach to this study was informed by my 9 years as a teacher of LTEL students. Based on those 9 years of observation and working both with LTEL students, and interacting with all of the other elements that comprise school culture, I approach this study with a belief that the culture and climate of a school impacts students' relationship to school and learning. I have witnessed regularly how the culture, the environment, and the atmosphere of a school towards bi-cultural students impacts how they are viewed by the school culture and how bi-cultural students view themselves in the context of school. My experiences as an ELD teacher have also informed what I want to know, and the types of questions that I asked.

Validity. Underpinning the qualitative approach to research is the understanding that reality, and how individuals perceive reality, is relative to the experiencer (Merriam, 2009). This relativity can lead to findings being influenced by the researcher's interpretation. Merriam (2009) suggests that there are ways that a researcher can ensure degrees of validity in their findings. She suggests several techniques to ensure the internal validity of the research and accurate representing of the views of the research participants. I will employ the following techniques in order to enhance the validity 
vigor of the findings: member check, triangulation, colleague check, and statement of my experiences.

Member check. Merriam (2009) proposes this as a way to give study participants the opportunity to participate in interpreting the findings. This involves taking, "the data and tentative interpretations back to the people from whom they were derived" (Merriam, 2009, p.54). Maxwell (2005) refers to this checking the data with research participants as respondent validation. Maxwell states that "this is the single most important way of ruling out the possibility of misinterpreting the meaning of what participants say... and the perspective they have of what is going on (p. 111). He further states that not only are respondent validations useful as a check to see if the interpretations derived are plausible but they also provide a way to reveal our "own biases and misunderstandings" (Maxwell, p. 111). I mailed to each of the participants a printed transcript of their interviews and I let them know they were welcome to add to their interviews or to make changes. Member checks provided participants the opportunity to review their transcripts and afforded them the opportunity to modify or clarify their responses. However, even though each participant thanked me for sending them a copy of the transcript none of them ever volunteered any comments on it,

Triangulation. Triangulation is the use of multiple sources of data, data collection or using multiple sources to check and cross the data collected for reliability (Merriam, 2009) In the case of this study, triangulation involved member checks as a 
follow-up to the one-on-one interviews for participants' feedback. Colleague check-ins or debriefings gave me a chance to reflect on my assumptions and findings. Having the recorded interview transcripts professionally transcribed was another effort to ensure the validity and reliability of my data sources.

Colleague check-in. Through the proposal and dissertation process I have had opportunities to discuss my data and interpretation of my transcripts with colleagues. The processes of checking in with colleagues afforded me the opportunity to question and assess the validity of my findings and interpretations. The colleagues with whom I have discussed my research were 2 fellow ELD teachers in my school district. One colleague read through 4 of the interview transcripts and she highlighted sections of the transcripts that stood out to her. I noticed that we high-lighted similar sections though her comments tended more towards noticing students observations about teacher support. Having conversations regarding my research experiences and findings helped me to verify my findings.

Statement of experience. Positioning myself through revealing and reflecting on my assumptions and experiences in working with LLTEL, helps "the reader to understand how a researcher's values and expectations influence the conduct and conclusions of the study" (Merriam, 2009). Positioning also helps me to reflect on my interpretation and what I consider important to high light with coding. Merriam refers to 
this strategy as researcher's position or reflexivity. This further degree of transparency strengthens the validity of the study.

\section{Confidentiality, Records \& Distribution}

All of the participants invited to participate received a written description of the study. IRB approval protocol was followed and signed Informed Consent forms were required for all participants, see Appendix A. All project data, such as digital data from interviews, surveys code lists and notes are secured in locked file cabinets in the home of the researcher. I know the name of each participant but for the findings pseudonyms were selected for each participant. Code lists will be kept separate from the data so as not to inadvertently reveal the identity of any participants.

Results will be shared with my adviser, and dissertation committee members. Results may also be published in my dissertation and may be presented at professional conferences. Participant confidentiality will be maintained. The data and files will be kept for a minimum of three years in locked files.

\section{Summary}

This chapter has discussed the process of qualitative research that was undertaken for this research. The intent of the research was to explore the perceptions of former Latino LTEL regarding their high school experience as LTEL. Data for this study were collected through interviews and questionnaires. Participants were recruited through 
social media and referrals from their friends. Each participant completed a demographic questionnaire and during the $30-40$ minute interviews were asked 14 questions that were developed in order to answer the research questions.

After many coding sessions where sections of interviews were labeled with 1-3 word phrases over 90 codes emerged. These codes were then categorized into 4 overarching thematic code families. These thematic code families are: affective needs, acculturation, identity and academic support. It is anticipated that the results of the study will inform ELD decision makers and school administrators in their efforts to provide ELD programs and school environments that support the academic acculturation and affective needs of Latino LTEL. It is believed by this researcher that supporting LTEL's acculturation and affective needs will

Chapter 4 presents a detailed analysis of this study's data collected through interviews and questionnaires. I explore the participants' experiences, perspectives and reflections on being a Latino LTEL student in high school. 


\section{Chapter 4}

\section{Findings}

Nationwide schools are focusing efforts on reconfiguring their curricula and instructional practices to address the needs of LTEL (Faltis \& Coulter, 2008; Hakuta, 2000; Olsen, 2010). This research examines another side of the LTEL concern- the role of school culture as related to the academic acculturation and success of Latino LTEL. The purpose of this study was to describe and explain recently graduated Latino Longterm English learners' perceptions of the impact of their school's culture on their academic and affective acculturation. Latino LTEL have insights to share about how schools could more effectively and proactively meet the socio-cultural, academic and affective learning needs of Latino LTEL students in order to support their academic success.

This chapter presents the voices and perspectives of participants who were classified as Latino LTELs' when they were in high school, and analyzes the themes that arose during data collection and the coding process. The information presented in this chapter is organized according into the following sections: demographic characteristics of participants, participant profiles, themes in the data, participant recommendations and finally summary of findings. 


\section{Participant characteristics}

In Chapter 3, I discussed the questionnaire instrument that all participants completed; this data was used to provide basic demographic, socioeconomic, language and education background data. This information was culled from the demographic questionnaire that each participant filled out prior to their interview. The questionnaire can be found in Appendix C. This questionnaire was designed to collect information about how many years participants spent in K-12 US schools, their parents' level of schooling, participants first language, how old they were when they began speaking English and whether or not they were born in the US. I was also interested to see how they would self-identify when it came to ethnicity and socio-economic class. The data collected from the questionnaires was separated out into two tables. Table 4 contains information regarding age, birthplace, ethnic identity and socio economic data. Table 5 focuses on their education background. 
Table 4.

Participant ethnicity and socio-economics

\begin{tabular}{|c|c|c|c|c|c|}
\hline Name & Birthplace & Age & Ethnicity & Gender & $\begin{array}{l}\text { Self-identified } \\
\text { economic class }\end{array}$ \\
\hline Moises & Mexico & 20 & $\begin{array}{l}\text { Hispanic } \\
\text { Hispanic- }\end{array}$ & $\mathrm{m}$ & Lower middle \\
\hline Leon & US & 20 & American & $\mathrm{m}$ & Working middle \\
\hline Nayeli & US & 20 & Hispanic & $\mathrm{f}$ & Working \\
\hline Eduardo & Mexico & 21 & Hispanic & $\mathrm{m}$ & Lower middle \\
\hline Selene & Mexico & 20 & Hispanic & $\mathrm{f}$ & Lower \\
\hline Isabela & Mexico & 22 & Latina & $\mathrm{f}$ & Poor- lower middle \\
\hline Anna & Mexico & 19 & Hispanic & $\mathrm{f}$ & Working \\
\hline Ariana & US & 20 & $\begin{array}{l}\text { Mexican- } \\
\text { America }\end{array}$ & $\mathrm{f}$ & Medium \\
\hline Andrea & Mexico & 21 & Latino & $\mathrm{f}$ & Working middle \\
\hline Julius & US & 20 & Latino & $\mathrm{m}$ & Working \\
\hline
\end{tabular}

Table 4 relates that the majority of the participants, six, were born in Mexico and migrated to the US while in grade school. One participant, Isabela, moved here while in middle school. Participants, though all of Mexican descent chose to describe their ethnicity in various ways; six participants identified as Hispanic, three identified as Latino and 1 participant identified as Mexican-American. Four of the participants were males and six were female. In regards to economic class, I had to explain to many of the participants what is meant by these various economic levels. Three of the participants, who had taken college classes that had to do with sociology, understood these terms. For 
those to whom I had to explain socio-economic levels, I tried to give a few options so they could choose how they wanted to define their family's economic status. Half of the participants identified their economic background as middle-class, the others classified themselves/their families as working class.

Table 5, an education background and profile of the participants, gets to the heart of many of the questions that are discussed by researchers when exploring the questions regarding LTEL: parents' education; age participant first spoke English; how many years they were schooled in the US; participant's home language; and whether participant had been educated in their home language (Cummins, 2000; Hakuta, 2000; Olson, 2010). They are all considered factors that impact a student's development of English language proficiency. The majority, six, of the participants were born in Mexico and migrated to the U.S while in grade school. One participant, Isabela, moved here while in middle school. All of participants' first language was Spanish and they all received ELD services throughout their high school years; Eduardo exited ELD services for his senior year. The participants who were born in the US started speaking English when they began either kindergarten or preschool. One question that was not on the questionnaire, but which I asked each participant during the interview, is whether they had received any schooling in their home country or language, and six of them had. The participants' range of receiving ELD services was from seven to thirteen years.

The "Parents Education" column contains data for both parents when applicable. Not all of the participants knew both of their parents' level of education, but when they 
did know the mother's level was written first. Most of the participants' parents, seven, did not attend high school. Out of all the participants' parents, only three graduated from high school and, one parent attended a technical college for two years.

In terms of the participants' levels of education, all but one of the participants has taken one or more college classes; though only two of the participants have gone beyond 2 semesters of college attendance. One has graduated from a four- year university, and one is currently attending a four year university. The other participants, who have taken some college classes, are supporting themselves as they intermittently make their way through community college. Moises attended a Certifies Nursing Assistant (CNA) credential program and works as a CNA. Several of the participants were undocumented which made it difficult to procure jobs and apply to community college. Those without documents have recently been able to take advantage of Obama's and Oregon's Dream Act program and are working and attending school and working towards certificate programs in cosmetology and the other in dental hygiene. Two of the participants are parents, one is a single mom and the other parent is married and has not yet attended college.

Spanish remains the home language of all of the participants. Two of the participants who are mothers are speaking Spanish or as they both wrote on the questionnaire, Spanglish, to their children in their homes. The interviews, questionnaire, and letter of research consent were conducted solely in English, for, as is the case with many LTEL, the participants all expressed that their English is better than their Spanish. 
Table 5 .

Participants' education background

\begin{tabular}{|c|c|c|c|c|c|c|}
\hline Name & $\begin{array}{l}\text { Years } \\
\text { schooled } \\
\text { in } \\
\text { Spanish }\end{array}$ & $\begin{array}{l}\text { Age } \\
\text { Spoke } \\
\text { English }\end{array}$ & $\begin{array}{l}\text { Years in } \\
\text { US } \\
\text { schools }\end{array}$ & College & $\begin{array}{l}\text { Parent's } \\
\text { education }\end{array}$ & $\begin{array}{l}\text { Home } \\
\text { language }\end{array}$ \\
\hline Moises & 3 & 8 & 10 & $\mathrm{y}$ & hs grad & Spanish \\
\hline Leon & na & 3 & 13 & $\mathrm{y}$ & $\mathrm{ms}$ & Spanish \\
\hline Nayeli & na & 6 & 12 & $\mathrm{y}$ & 6th gr & Spanish \\
\hline Eduardo & 2.5 & 8 & 9 & $\mathrm{y}$ & $8 \mathrm{gr} / 9$ th & Spanish \\
\hline Selene & 3 & 8 & 10 & $\mathrm{n}$ & hs grad & Spanish \\
\hline Isabela & 5 & 11 & 7 & $\mathrm{y}$ & $\mathrm{ms} /$ tech & Spanish \\
\hline Anna & 2 & 7 & 11 & $\mathrm{y}$ & $\mathrm{ms} /$ elem & Spanish \\
\hline Ariana & na & 4 & 13 & $\mathrm{y}$ & $\mathrm{ms} /$ elem & Spanish \\
\hline Andrea & 1 & 4 & 13 & $\mathrm{y}$ & $\mathrm{ms}$ & Spanish \\
\hline Julius & na & 5.5 & 12 & $\mathrm{y}$ & ms/elem & Spanish \\
\hline
\end{tabular}

Note. $\mathrm{ms}=$ middle school, hs $=$ high school, elem $=$ elementary school.

\section{Summary of participant characteristics}

All of the participants graduated high school, it took four of them more than four years to graduate. Table 5 represents a summary of characteristic of the 10 the participants. Six of the participants were female and four of them were males. All of the participants' home language was Spanish growing up and remains Spanish. As of the time of the interviews only one of the participants had graduated from a university, another plans to eventually graduate with a bachelor's degree. Seven of the participants 
have taken from one college course up to two years of college coursework; only one participant has yet to graduate from college.

Table 6.

Summary of Participant Characteristics. $n=10$

\begin{tabular}{ll}
\hline Characteristic & $\mathrm{n}$ \\
\hline Birthplace & 4 \\
US Born & 6 \\
Mexican Born & \\
Gender & 4 \\
Males & 6 \\
females & \\
College & 1 \\
3 or more years of college & 2 \\
1-2 years of college & 6 \\
Less than 1 year of college & 1 \\
No college & 10 \\
\hline Home language Spanish &
\end{tabular}

\section{Participant Interviews}

This research sought insight into the lived school experiences of Latino English Learners and their perceptions of what it is to be a Latino LTEL. The participants' perceptions of their high school education experiences are valuable sources of data; their perceptions of their school years were constructed through formative experiences and interactions with teachers, staff, administrators, and other students. Through 
understanding their perceptions and experiences we may find ways to assist schools and EL to bridge the opportunity gaps that local, state, and national educational testing scores and dropout rates reveal in relation to Latino EL. The research questions that I expected would be answered by means of these interviews:

1. What are recently graduated Latino LTEL perspectives of how their high school supported or did not support their academic acculturation while in high school?

2. What are recently graduated Latino LTEL perspectives of how their high school supported or did not support their affective learning needs?

\section{Code family themes}

The data from this study's participant interviews may well provide a deeper understanding of the complexities of acculturation that Latino LTEL students' experience. The many individual codes that emerged from participant interviews were organized into code families that represent overarching themes. The themes and patterns that stem from the interview data provide insight into how recently graduated Latino LTEL students perceive and experience their place in their schools' culture and their educational attainment. The code families, and the themes they represent, are discussed in the following sections and represented in Table 7 . The code families are: affective needs; acculturation; academic support; and identity.

This section is organized according to the code family themes found in Table 7. Many of the codes, with which the interview segments were labeled, fit into more than 
one of the code families; this is not surprising as students have many interactions within the course of the school day, and each interaction may impact them in multiple ways. Hence, their interactions may impact their willingness to acculturate; their access to academic support or willingness to pursue academic support; their sense of belonging or not belonging to the school culture; and how their identity or self-perception of themselves as learners developed. (Li, 2010; Lopez, 2010; Mehan, Hubbard \& Villanueva, 1994; Osterman, 2000; Oyserman \& Destin, 2010; Roland, 2008; Rubin, 2007; Schumann, 1986; Spencer. 1999). Table 6 lists the code families and provides some examples of the codes subsumed under these families and tells the number of codes and quotes associated with each family (Appendix E has a full list of the codes). 


\section{Table 7}

Thematic code Families.

\begin{tabular}{|c|c|c|}
\hline Code Family & Definition & Example of Codes \\
\hline $\begin{array}{l}\text { Academic } \\
\text { support }\end{array}$ & $\begin{array}{l}\text { School provided/didn't } \\
\text { provide access to } \\
\text { resources that helped } \\
\text { LTEL navigate school } \\
\text { system, academics and } \\
\text { culture. }\end{array}$ & $\begin{array}{l}\text { Codes (12)-lack of connection to teachers; + ELD } \\
\text { support; academic advice; academic preparedness; } \\
\text { academic support; classroom connection } \\
\text { Quotes (44) }\end{array}$ \\
\hline Acculturation & $\begin{array}{l}\text { Refers to the school } \\
\text { adapting to new } \\
\text { culture groups and } \\
\text { supporting/not } \\
\text { supporting Latino } \\
\text { students' needs and } \\
\text { adaptation to the } \\
\text { school culture. }\end{array}$ & $\begin{array}{l}\text { Codes (34):lack of access to resources; -lack of } \\
\text { connection to school culture; lack of connection to } \\
\text { teachers; lack of support;-perception of Latinos; - } \\
\text { relationships with teachers; -school connection } \\
\text { Quotes (115) }\end{array}$ \\
\hline $\begin{array}{l}\text { Affective } \\
\text { needs }\end{array}$ & $\begin{array}{l}\text { Students' affective } \\
\text { needs include: sense of } \\
\text { belonging, feeling } \\
\text { good about themselves } \\
\text { as learners, and feeling } \\
\text { represented in the } \\
\text { school's culture }\end{array}$ & $\begin{array}{l}\text { Codes (17)-lack of access to resources; -lack of } \\
\text { connection to school culture; + ELD support; } \\
\text { +school support; +teacher connections; classroom } \\
\text { connection; eld support; perception that help not } \\
\text { equally available to Latinos; relationship at } \\
\text { school; school belonging; school connections; } \\
\text { sense of belonging/eld } \\
\text { (Quotes 63) }\end{array}$ \\
\hline Identity & $\begin{array}{l}\text { Self-perceptions as a } \\
\text { learner developed } \\
\text { through school } \\
\text { interactions. }\end{array}$ & $\begin{array}{l}\text { Codes (35)-Latino culture not represented; - } \\
\text { perception of Latinos;+Latino culture represented; } \\
\text { adult connections; ELD main friends; Latino } \\
\text { friends; perception of ELD students struggling } \\
\text { with issues of racism } \\
\text { (Quotes 75) }\end{array}$ \\
\hline
\end{tabular}


Affective needs. The daily interactions that students have with their teachers, staff, and other students are factors that impact a student's perception of themselves as a learner, and what they feel is possible for them to accomplish academically (Lopez, 2010; Osterman, 2000; Oyserman \& Destin, 2010; Roland, 2008). As mentioned in Chapter 2, there is significant research that indicates that when students' affective needs of belonging, acceptance, inclusion and feeling valued are not met, they lack a positive sense of connection with their teachers and peers, and their academic achievement suffers. Research also indicates that students' academic achievement flourishes when their affective needs are met (Booker, 2007; Faircloth \& Hamm, 2005).

As I coded for affective needs, I listened for whether or not participants expressed a sense of connection, acceptance, inclusion, encouragement, and represented in their school. Table 7 lists the codes that were grouped under the theme or code family "Affective needs" the full list of codes is found in Appendix E. When there was a positive sense of affective needs being met I either put a + sign in front of it or left it as it was. Conversely when participants expressed a lack of their effective needs being met I either put a - sign or wrote negative in front of the code. Not all of the codes had a negative or positive connotation assigned.

Affective needs met. Most of the participants had at least one adult in their high school to whom they felt they could turn when they needed support and assistance. All of the participants mentioned their ELD teachers and classes were resources for their 
sense of belonging, acceptance, inclusion and validation. A few of the participants had a counselor or another teacher or staff member who helped them to navigate their senior years in high school. Isabel, who graduated from college and is currently applying to graduate school, was one of the participants who developed positive relationships with ELD teachers, her counselor and one other teacher, who assisted her with signing up for AP classes, writing her college essay, and applying to college.

The ESL teachers were really the ones that ... were so aware of kind of like the needs that we had...Miss Thompson, I remember she was so helpful. She taught science, but she was super helpful about, like, everything else and she was like, "Oh, do you know you can do this?", AP classes and stuff like that. (Isabel, interview)

Julius, when asked about feeling supported at school, told me about his graduation ceremony. His counselor when she found out he was not going to attend the graduation ceremony because he didn't want to pay all the fees, insisted on paying for his graduation regalia and she wouldn't stop insisting on his attending graduation ceremony until he agreed to participate.

Oh no, I didn't want to walk. I didn't want to spend this much money on that for only one day, you know?" I don't really care for graduation. I wanted to get my diploma and that's it, like bounce like bye, you know? She's like "No, you have to do it, please. I'll get it for you, Eric. Please go, please go." Yeah. I was like, "Oh wow, they really do want me to be like on stage." For me, I didn't care, but that was really nice of them. I would always remember that (Julius, interview). 
Affective needs not met. Participants' interviews revealed strong feelings about their sense of belonging and connections to school. For the most part, all participants revealed that they had a strong sense of being different culturally and didn't feel that their high school did much to bridge that gap. Nine of the 10 research participants expressed that they did not have a sense of belonging or feeling part of their school's culture. All of the participants also expressed that their friends at school were mainly Latino and occasionally ELD students from other cultures or ethnic groups.

Selene, who moved to the US in $4^{\text {th }}$ grade, explained how this feeling of disconnectedness manifested at school assemblies.

We would have the assembly and all of the Mexicans would sit in the corner. It was because it didn't appeal to us. I guess because it was a whole different culture and it was not ours and we didn't - I guess we understood it, but we didn't want to accept it, because I guess we wanted to hold onto our culture and it was just very different or like, the - the sense of, like, our parents not going through the whole thing. We didn't know, so it was all new, so we were not accepting with the whole culture in general, so we kind of stayed apart, aside. And I remember I didn't feel part of it at all, I remember not even wanting to stay in the gym. (Selene, interview)

Andrea also had a sense of attending a school that was a foreign culture; this led to her feeling like she didn't belong to the mainstream culture of her high school.

I always felt that I wasn't part of their group. They always made me feel that I didn't belong there, so why try. I mean I did have white friends, but it was mostly because they would speak to the Latino, like they were part of the Latino group I always felt that I wasn't part of their group (Andrea, interview). 
That sense of being an outsider was reinforced by how she was treated by school staff. She expressed that when one of her teachers was out on maternity leave there was a long term sub that did not make Andrea or other Latinos feel valued or accepted. "She would treat me - like Latino people-- a different way than she would treat the others."

Many participants expressed that one way they had dealt with the stresses of going to school or to classes where they didn't feel a connection or understand what is going on was to cut school frequently. This way of dealing with this sense of disconnect, could be an example acculturative stress -- which is explained in the next section on acculturation (Garcia-Vasquez, 1995). Ariana, when asked about adult connections at school, responded that in her opinion most Latino students,

They feel that teachers don't care about them. They just slack off and I know that because I know I've been there too, and I just - if I feel like the teacher doesn't care about my education, I say, "What's the point of me even going there? (Ariana, interview)

An issue that most of the participants discussed was the alienation their families experienced because they didn't speak English and didn't understand the education system in the US. Isabella felt that reaching out to Latino parents wasn't happening when she was in high school.

I don't think the school was addressing our culture or our needs appropriately. I feel like they needed a lot more resources and they needed to be more sensitive to kind of like the socioeconomic background issues. There's a lot going on in our family and there's a lot of - I feel like it's so different because we're the ones showing our parents what's needed a lot of the time. (Isabella, interview) 
Isabella further explained that because Latino EL were translating and relaying information to their parents about school, they were then able to manipulate their parents through withholding information or not accurately representing school information. She expressed that she and other Latino students were carrying a different load than their peers, and the school didn't seem to be aware of their different needs.

I mean not only are we going through puberty at that time, which is crazy, but we're also you know, we're in a different country, in a different setting, and different culture so I feel like a lot of it needs to be approached from a very friendly way instead of just, like, oh, "We're the school. We make the rules. Here, adhere to them" (Isabella, interview).

Acculturation. As discussed earlier, socio-cultural theory frames learning as a dynamic state where learners are responding to their school environments. When schools provide access and pathways to academic success for Latino LTEL, through concerted policies, they are enabling Latino LTEL to acculturate academically. In order for an immigrant group to adapt to the social institutions of a dominant culture, it is necessary that the immigrant group be allowed to adapt and provided with resources that facilitate their integration. For the participants in this research, and for many other bi-cultural and EL students, if they are not shown how to navigate school culture and aren't explicitly invited to participate, they don't learn how to perform academically. Without schools explicitly scaffolding bicultural students' acculturation, many of these students may end up feeling like outsiders or like failures. "Often, the acculturation process results in conflicts stemming from the minority culture coming into contact with the majority 
culture. The conflict in turn creates stress which elicits coping mechanisms to manage the conflicts" (Lopez, 2010, p. 9).

Acculturation: needs met. For the majority of the participants their English language development classes were where they experienced assistance in navigating school and societal norms and procedures. Leon, who for his senior year was elected class-vice president, was aware while he was in school that his ELD classes provided more than English language instruction and were helping him to acculturate to "the school environment".

It taught me to be more comfortable with the way that I - that I am, to get more adapted to the environment, to the type of school environment ...they gave me more - more inspiration or more motivation or more -confidence in my academic language/expression (Leon, interview).

The participants, who were in ELD classes from 3-4 years during their high school years, all expressed that ELD teachers and classes were where they learned to navigate school and US culture. As Selene said when asked how her ELD classes impacted her acquisition of academic language. "I guess just expanding my vocabulary and understanding, the everyday things that you don't know about the English speaking society."

All of the participants expressed that their ELD classes were where they felt that their teachers were looking out for them and helping them to navigate school processes 
and issues. Nayeli, who was born and raised in the US, perceived that most teachers had negative concepts about Latinos, expressed,

I just felt like very judged by other teachers because they didn't understand, like my English. But when I went into ESL, like, she was very patient and very loving, and she always asked us if, you know, we had any problems (Nayeli, interview).

Anna also voiced that ELD was where she felt comfortable asking for help. Her ELD teachers helped her, "with some problems that I was going through, like my senior year, she helped me get more motivated for school and stuff. She definitely helped out a lot."

Julius, who while in high school didn't have much of a sense of connection to school, experienced that his ELD classes were supportive and made sure he was aware of academic and social opportunities.

They help you with everything. They asked you questions like, do you need help with this, do you need help with that, how is it we can be of help to you? They were really supportive for everything. It was really good (Julius, interview).

Acculturation: needs unmet. The major themes or issues presented in this section on acculturation have to do with lack of access to resources. All of the participants' parents were native speakers of Spanish and the majority of the parents had limited education experience with secondary schools. The participants expressed that their parents weren't able to help them navigate school, and in fact as students, participants 
often had to pilot their parents through understanding school culture and requirements. Isabel expressed this frustration well. "Not everyone spoke Spanish. Like, our parents didn't have like, a resource other than, Aguilar to [her counselor] - to reach out to, there wasn't more cultural awareness or readiness."

Every participant expressed that their parents weren't able to help them understand what they were required to do at school to be academically successful. This complicated their access to academic achievement and made it necessary for them to find assistance at school. Eduardo, and all of the other participants, expressed that they didn't know where to turn for help navigating school, or had difficulty finding people to explain school processes and procedures.

For me, my parents they didn't have education, they didn't graduate, didn't even finish high school. I didn't have support either from them. So I just had to learn on my own what school was like. And I didn't have actually the background knowledge of school (Eduardo, interview).

Some of the participants expressed that the school as an institution didn't quite know what to do with ELD and bi-cultural students. A few, like Isabela, expressed that the only time the administration seemed to notice Latino students was when they were in trouble.

I feel like our school didn't do a good job at letting our other students know, we were there or that we were - you know, we were part of the team. I don't feel like a lot of administrators at the time were - I'm not gonna say aware, but I don't think they cared much about that population until - I think to them, it was more of $\mathrm{a}-$ the troublemakers. They assume we don't care about school, because we tend 
to have, you know, not-so-good grades and don’t speak English well (Isabella, interview).

Isabela also expressed that teachers didn't seem to realize that language really was a barrier that ELD students had to navigate and that she wished more teachers took that into consideration. Rather than making students reveal in front of the class their lack of comprehension she wished teachers made the effort to check in with students.

Language was a barrier. So, if they would've taken that into consideration, I think the students sometimes - I remember I was afraid of asking for help, so instead of having the students ask for help, maybe have them [teachers] reach out to you (Isabella, interview).

Many of the participants struggled in school, and not just academically, but socially as well. As discussed above, it sometimes came from the struggle to adapt and perform well academically and socially in a setting and culture that though familiar was equally foreign to them. The acculturative stress that resulted often led students to feel unmotivated. Nayeli discussed how the lack of connection to school and teachers sometimes made her and her friends feel.

They feel that teachers don't care about them. They just slack off and I know that because I know I've been there too and I just - if I feel like the teacher doesn't care about my education, I say, "What's the point of me even going there?" (Nayeli, interview).

Selene, and all of the other interviewees, articulated a feeling of not really having a sense of what was going on in high school, "- I guess we were going along with 
whatever was going on, but nobody really helped us, except for our ELD teachers". Andrea also voiced a sense of feeling at a loss. After four years attending the same high school, when it came to her senior year she voiced that she didn't have a connection with her counselor or any adults in the school except for her ELD teachers, and she wasn't quite sure what she was supposed to be doing, "I didn't have that communication with any other teacher but my ELD teachers. Like when I needed something or when I had a question or something or like, for my senior year, I was just lost.”

Identity. How we are seen by others and what others think we are capable of impacts what we believe we are capable of (Jimenez, 2000; Lopez, 2010; Oyserman \& Destin, 2010; Usher \& Kober, 2012). Latino LTEL students have identities imposed upon them by how they are categorized in our schools' data and records. They are categorized by way of their cultural identity; classification as a "minority"; Latino; and as an EL. As discussed in Chapter 2, in the section on socio-cultural theory, how students see themselves in the context of their school and community can influence students' identity formation, impacting their, "values, feelings of competence and relatedness, and goalsetting” (Usher \& Kober, 2012, p. 6) Peers, teachers and school staff's preconceived notions of Latino EL inform how they respond to Latino EL throughout the school day. The messages Latino LTEL receive about themselves, and their culture group, influences their sense of academic competence and belonging.

Two of the questions that were asked in all the interviews were whether the participants perceived that being Latino or being an ELD student impacted how peers, 
teachers or other staff perceived them. The major themes that emerged in this code family is that participants felt that, as both Latinos and ELD students, they were perceived as not equal academically to their mainstream peers. Quotes from the interviews reveal that participants' self-identity as Latino students were impacted by how they felt they were perceived by their peers and school staff. As you will read below, all of the interviewees communicated a sense that in relation to their schools' culture they experienced being outsiders.

Of the codes that were aggregated under the theme Identity, some codes had positive and some had negative connotations; 16 out of 37 of the codes that make up the code family Identity had negative connotations. It seems that all the participants struggled with negative stereotypes associated with both Latino culture and being ELD students. In their interviews they all conveyed that as Latinos and ELD students they were perceived by their peers, teachers, staff and administrators to be less competent than other students and/or less respected as learners. You will read in some of their quotes how they've inculcated into their narratives that culturally Latinos are not serious students.

This section on identity is divided up into Latino identity and then ELD identity. Dividing the topic of identity into these sections facilitates a deeper understanding of the stereotypes that these former Latino LTEL struggled with. -- I do recognize that as high school students the participants' identities encompassed more than being Latino or ELD students. As this research is focused on understanding the interplay of these 2 perceptions 
and school acculturation choosing these 2 aspects of their school identities is deemed sufficient.

Latino identity. Many of the participants' sense of positive identity in school came from their friends who were also Latino. Even though all expressed feeling like outsiders in their high schools, they found ways to express their culture with in a school environment that wasn't yet providing opportunities for their Latino (and other nondominant culture groups) to access participation in the development of the school culture. Some of the participants, like Isabela, who felt very aware of stereotypes teachers had about her as a Latina, expressed as they progressed through high school they developed the attitude of, "I'll show them Latinos can"

Leon had a positive spin on his high school experience. In his junior year he was elected class president, however administrators decided that since he didn't have leadership experience, that even though he received the most votes he would be made class vice president. His feelings about this were complex, as he had actually completed a yearlong Latino leadership course for high school students at Clackamas Community College. He had the attitude that it was all good but when he referred to the experience a few different times, "from what I heard is that I won, but I was cheated out of it". The experience of running for class president and speaking in front of a school brought him a lot of recognition and accolades. He was the first Latino student on the school's governing body which was a significant accomplishment. 
I mean, like I said, I was always nice to everybody. I was always helpful. I was always friendly to everybody, so in a way I have lots of friends... I felt part of the school because many people around the school knew who I was. The principal, the counselors, teachers, and even though people I didn't know, know about me, so that was nice. That was nice (Leon, interview).

Eduardo, saw himself as compliant of school rules and interested in getting an education, however, he experienced that mainstream students and his teachers assumed that he wasn't a serious student because he was Latino. "I think there was also this thing about Latinos being bad or being in gangs and stuff. And you being seen as that separates you from having that respect."

Moises volunteered that he wasn't the best student, but he did his best to stay out of trouble. In the beginning of the interview when I asked him to tell me about his school experiences, he spoke about how great school was. Then, when I asked him about whether he felt a part of the school he paused and then said, "No". The question seemed to bring up memories because his affect changed from a sense of it was all good to remembering the struggles he had as a student. When I asked about how being Latino impacted how he was treated by peers, teachers or administrators he voiced that he felt that he was often targeted by administrators because he was Latino. He had several experiences that reinforced this feeling. In school he was really interested in art and liked graffiti- he didn't see it as gang related but as art. One day while he was sitting at lunch drawing in his binder, the school's vice principal came up to him and asked to look at his artwork. She pointed to a drawing that was in his binder and then asked if he could take it 
out so she could look at it. She then proceeded to rip it up in many pieces explaining that it was gang related; the same afternoon she him brought to her office.

She brought me to her office and looked through my binder and looked at my other sketches. She brought in a man who showed a badge and said he worked gang prevention. They looked in my binders and found drawings they said had numbers, a 13 and 1 and 14, saying that it shows I was in a gang. I told them that they were just designs and I didn't see any numbers (Moises, interview).

Moises expressed that these kinds of incidents," made me not want to do art at school anymore." Another time the same vice principal saw him getting dropped off at school.

Ms. V gave me detention and suspended me when she saw me get out of a car with some people. When I asked why, she told me that those people were in gangs. I told her that they were my cousins and that I wasn't in a gang and they weren't either (Moises, interview).

As we spoke Moises several times referred to how Mexicans were not good students and that they got into trouble often because they deserved to. It seemed he had been inculcated with a perception of Latinos as students who regularly get into trouble.

Ariana, who'd had several interactions with school administrators regarding breaking school rules, seemed to feel that as a Latino, administrators and teachers didn't treat her in the same way as "the white kids".

To a white kid, you know, they would - they would sit there and talk to him and try to make him, you know, be cool and be calm. You know, just like try - try different methods - methods of getting him to stay calm and listen, you know. 
Where towards a Latino, you know, they would just be like, "You know, if you if you don't wanna stay here, you don't wanna listen, you know, then you can go.” Just get out, you know? Or send them to detention and stuff (Arian, interview).

Isabela felt that teachers often just didn't know what to do with Latino students and that they had stereotypes about Mexico that impacted what they thought she was capable of. "They would think, like, you were completely different, just because you, you know, were from Mexico. Like, they had the perception that you spoke Spanish and Mexico is like this -they thought Mexico was poor, undeveloped and just different."

Andrea named what she perceived to be the stereotype her peers and teachers had about Latinos; Latinos weren't “as capable”. As a student she was aware of negative perceptions about Latinos, she said that when she would walk into a class other students would stare at her, "It made me feel weird. Like, am I not capable of being in this class? You think that I'm not capable?" As she expressed her past feeling of indignation in the present tense, it seems that sense of not feeling like she was valued or respected by the main stream culture was still fresh in her mind.

Many of the participants expressed that they had experienced outright racism from other students. Julius shared with me the following experience.

This guy like, I sat - I was sitting down already and they told him to sit next to me. He's like, "I don't want to sit with a Mexican." And he's like, "Oh, sorry." I'm like don't be fake- don't be sorry, like it's who you are. You're - it's who you are and you're never going to change if you're going to just be like that forever (Julius, interview). 
He wasn't surprised by the experience; he expressed he wouldn't have wanted to sit next to a racist person anyway. After he shared this I asked if his teacher had intervened and he said no, she had just observed.

The participants all experienced, throughout their years in high school, negative stereotypes about Latinos. A few of the interviewees said they thought the negative stereotypes probably came from media or their parents.

Well, with students, I felt like they were already in their minds and maybe through their families they have - they already judged us before they even knew us because of stuff that goes on television or stuff - or like, you hear in the news or radio stations. ... A lot of the kids-they - sometimes they would look at me and they'll be like, "Oh, do you speak any English," like in a rude way, but you know, I kinda just avoided those people and just went my own way (Nayeli, interview).

She further said that she thought the staff's stereotypes about Latinos impacted how Latinos were treated: "the teachers and other students would get irritated with the culture, because we're loud and we just supposedly wanna party all the time and skip school."

Some of the participants' view of themselves as Latinos impacted their willingness to get involved and participate in school activities. Nayeli expressed that she didn't get involved in other school activities like clubs because she was self-conscious about her language. "I could have been more involved. I was probably too scared that my English or people would judge me because of my language I guess. Like, I didn't explain myself well to them." 
Andrea expressed that when it came to her Mexican culture, at school she was always aware of being different. She didn't necessarily believe it was racism. "I felt so out of place too, because everything was just, like-Mexicans weren't really acknowledged." She expressed that there just wasn't much awareness of or respect for cultures that were different from the "white" culture of her school.

ELD identities. Participating in ELD programs was a complex situation for the participants. All of the participants expressed that they felt good about their ELD classes. In their ELD classes they felt comfortable with their teachers and their peers. It was also in their ELD classes where they felt the most academically supported and where their affective needs were met. Anna voiced that,

Well, like, socially, we were always with the same people throughout the whole year. So you got to know the people in that little class, like, from different places and stuff like that. Academically, it was easier to give speeches, and the teachers had more patience and stuff like that. The classes were smaller so that teachers always checked up on you, you know? They always made sure you like, you're on track and like, with a larger group of people [referring to non-ELD teachers], it's just like, now that I'm teaching the class and not necessarily, like, focusing on each student (Anna, interview).

Even though the participants all appreciated their ELD classes and teachers they were not all comfortable with being identified as an ELD student; they felt that being in an ELD program had a negative stigma. Several of the participants expressed that their peers and teachers saw them as "having special needs" (Leon). Therefore exiting their ELD programs made them feel they were able to demonstrate that they were just as smart 
as their main stream peers. When I asked Andrea how she felt she was perceived by peers and teachers who knew that she was in the ELD program she replied,

Well, mostly teachers because they would know that you have ELD and I don't know. For some reason, they think that you're like more - how do I say - not dumb - but that you're not prepared kind of thing. So, like other students, once they get out of ELD, they're like, "Oh, I'm free." It's like, okay. You know, I'm there (Andrea, interview).

All of the interviewees voiced that being in ELD impacted how their peers and teachers perceived them. For the most part that perception seemed negative to them. Anna expressed that, "People look at you different sometimes because you had ELD and stuff like that, so people sometimes are like, "Oh, you still take ELD," you know?"

This sense that as ELD students they weren't as "capable" was a theme when it came to participants' perception of ELD services. All of the participants shared that in their experience their native English speaking peers and some of their Latino peers viewed ELD services as akin to receiving Special Education services. This was voiced by Leon,

When they found out I was an ELL person they would think that I'm a person with special needs, but I wouldn't let it affect me or anything because I know that if somebody tried to help me improve my English or the way that I talk or the way - you know, everything, so I thought of it more as a help thing ... so it didn't affect me at all whatsoever what people thought of me (Leon, interview).

Eduardo seemed to feel that being an ELD student in high school may have created difficulties in making friends with students who were from the dominant culture. 
"And friends who were Americans, I had-- it was just a few. I think making friends with them was hard."

Anna's classes were in an arts academy magnet school and she would go to the regular high school for ELD classes. When asked if she felt being in ELD classes impacted how students in her classes saw her she replied,

People look at you different sometimes because like, it's just like the third floor. You know how it's just like, the ELD part of the school, you know, so if you went up there, you had ELD and stuff like that, so people sometimes are like, "Oh, you know, you still take ELD," you know? Like, it's kind of like, "Why are you still in ELD?" Or, "Your English is fine." Like, "You shouldn't be in that program," kind of a thing, and then some people were like, "Oh, you guys don't learn what we learn," you know, kind of like, a lower level than regular (Anna, interview).

Selene talked about experiences in some of her core classes. She felt that her teachers assumed that as ELD students, "they thought we were dumb because we didn't have the same knowledge as other students". When I asked her for an example, she told me how some of her teachers would have all the ELD students sit together in one area of the class. Then, when the teacher would check for comprehension they would turn to the ELD section of the class and start calling out names of the ELD students individually and ask if they understood. Selene perceived this as a shaming experience and that it communicated to the other students in the class that ELD students were not as bright as their mainstream peers. 


\section{Academic support.}

The main theme that emerged in this code family is the lack of academic support the participants received while students. As you will recall in this chapter's earlier discussion about the demographic questionnaire and home language and education, none of the participants' parents had English language proficiency. As well, you will recall that of all the parents of the participants only 2 of the parents graduated from high school; hence, the research participants didn't have access to familial academic support so receiving support at school was crucial to their academic success.

All of the research participants expressed that they had an idea that academic support was possibly available, but the majority of the participants, 8 , expressed that they either didn't know how to access academic support from their core teachers or they didn't feel comfortable asking for help. From their accounts, it seems that outside of their ELD classes they did not experience on-going teacher support from their core content teachers or administrators.

Academic encouragement. While in high school, ELD classes were where all of the participants expressed they felt the most comfortable asking for help. They all expressed that they didn't usually have to ask their ELD teachers for help as their ELD teachers regularly proffered assistance and checked in with them. In order to develop academic language proficiency ELD students do need scaffolded academic support.

Two of the participants graduated from small magnet schools, and at their magnet schools they did experience that their teachers were academically supportive. Anna, who 
attended an arts academy charter school and went to a regular high school for ELD, experienced that the majority of her teachers did check-in with her,

They'd be like, "Are you sure, you're getting the material," you know? "Like, do you need, help or something? Maybe to make sure, I understood it. Some didn't really know I was in ELL like, it didn't make a difference and you know, I was treated like everyone else. (Anna, interview)

Leon, who, from his interviews, seemed to feel very comfortable accessing school resources also expressed that he was able to access help from his teachers outside of class. He experienced that when he expressed a need for help or didn't understand what was going on in his classes teachers would let him know they were available for after school. "You can stay after school and I'll tutor you or if you study this," I mean every teacher so far that I had, if I needed help, or if I had trouble, they would always help you."

Isabela for her senior year in high school refused ELD services and was encouraged by her counselor and another teacher to take Advanced Placement classes. She signed up and took the courses, one of which she failed and the other she got a C. She expressed that it was challenging because of the language and her writing skills in English.

I took AP world history. I took AP Spanish. I took advanced psychology. And that was great, but I still struggled and I don't know if this is just mainly because of my English as a second language, but I struggled a lot with my writing. (Isabella, interview) 
Unfortunately there just wasn't enough academic support within the AP classes for her to be successful. But she expressed the classes did give her a sense of what college would be like.

Academic support: lack. Eight out of the ten participants expressed that, outside of their ELD classes, teachers rarely reached out to them when they were struggling or made an effort to check-in for content understanding. Eduardo moved to the US early in his schooling. By his junior year he had been speaking English for 9 years and he was doing well in most of his high school classes. During his junior year of high school, to prepare for the rigors of college, he decided to take 2 Advanced Placement classes (AP) classes, AP English and AP history. The challenges of AP classes and the lack of academic assistance provided really impacted his self-perception.

Especially in my AP classes, that's where I didn't receive any help at all. Even though they knew I wasn't doing so well, they never really helped me. They just told me to drop out of the class. I just didn't know what to do, so I just stopped going to school. I felt like a failure. (Eduardo, interview)

Eduardo also discussed how the lack of academic support impacted how Latino LTEL thought about their futures after high school. "And they don't have that support from teachers, parents, counselors, or anyone around the school. So they think, if it's already hard for them why should they continue for college, that's even harder".

Selene communicated that for most of her years in high school she really didn't have an idea of what was going on in school. Not just academically and in her classes but 
also understanding what kind of academic and extracurricular opportunities were available. She reflected that most teachers probably didn't realize that she and her peers were attending school in a culture that was foreign to them, and there were few resources directed towards helping them navigate it.

I remember a lot of students knew what to expect because of their older brothers or their parents had been to a high school and they could ask them. They knew, but we were just like - I guess we were going along with whatever was going on, but nobody really helped us, except in ELL. (Selene, interview)

Nayeli too experienced that teachers didn't check in with them to make sure they understood class content. She voiced that often she, and other Latino LTEL in class, found themselves not having any idea what the teacher was talking about, "we would just sit there, we were gone, and everybody else was understanding, but I guess it was like—-how do you say it? Like a bar, and we were here and they [main stream students] were there" (she used her hands to demonstrate 2 divergent levels of comprehension).

\section{Participants' suggestions for supporting Latino LTEL's academic and affective needs}

One of the premises of this research is that prior Latino LTEL may have insights and recommendations to offer about how we can more successfully serve the educational needs of our Latino EL. Towards the end of each interview, the following two questions were asked of all of the research participants. 
- How could the high school you attended better serve the needs of their English Learners?

- What would you tell a high school administrator to help them provide a socially and supportive environment for their Latino EL students?

In response, there were three main themes each interviewee discussed as areas where support is needed for Latino EL, they are: the culture gap between their parents, their home lives, and school expectations; the need for administrators to get to know Latino students and facilitate awareness of minority culture groups within the school; for the school to reach out and help Latinos to get involved and be successful.

Culture gap. The recommendations that interviewees put forth really high-light the overarching sense of cultural disconnect that Latino LTEL experience. Many of the participants articulated that the school wasn't sufficiently aware of their students' Latino culture, needs and challenges. As was evidenced in the section above, students expressed a need to be understood and welcomed into the school culture as a Latino. Several participants recommended that administrators take time to learn about the cultures of their bi-cultural students. Moises voiced that he thought "administrators could make sure people understand other cultures". He also felt that schools should "try to have teachers from other cultures so they can understand the experience of brown kids".

Cultural differences between schools in Mexico and the US, their parents' level of formal education, and level of English proficiency; were some of factors that impacted participants' academic success. Each participant shared that they, and their parents, 
struggled with understanding all that was expected of them. The challenge of being aware of, understanding and following school requirements and expectations impacted their sense of belonging and ability to be engaged. Eduardo suggested that more academic advising for parents and students could bridge this lack of understanding and facilitate Latino LTEL academic success.

I think counselors have to be more involved. They should have a time to talk to students individually, like towards the end of each term. What their struggles were during their classes. And what can people in the school do to help them.

(Eduardo, interview)

Selene felt that schools need to be aware that their school traditions and activities are old and based on a school population that was homogeneous. She expressed that schools could make changes to make sure other, new cultures to the school, also feel part of the school.

They should be trying to connect with us or putting some of our culture - making our culture and I'm talking the Hispanic culture, but other cultures too, you know, the ones not from Europe. Help make them feel part of the school. Make new traditions that include everybody, not just the regular 50 years ago tradition that's been there in the high school for that long. That's the best way to start. (Selene, interview)

Nayeli, whose mom left school after third grade and whose dad finished sixth grade, felt that for Latino students to be successful in school, schools need to reach out to Latino parents. “The parents are the keys to the children's success. Our parents come from a different culture and the way they think about school is so much different from 
Americans." All of the participants felt that their parents' experience of school was so different that they weren't aware of how to support their children to be academically successful.

Isabela felt that some principals just didn't reach out to Latino students. She thought maybe they felt constrained by not understanding Spanish or Latino culture. She expressed that if they just made more of an effort to bridge the culture gaps that it would make Latino students feel acknowledged and respected.

I don't remember his name, but, he had a meeting with me and my mom my freshman year. He was super nice and he was the principal. I can't remember his name, Mr. G, he spoke very little Spanish, but he was trying, and I feel like all you have to do is try. Try and be approachable. Try to approach us and try to help out... I feel like they [the administrators] are limited. They would be like, "Well, why? We don't speak Spanish," And then they don't - they don't try...I feel like they needed to just try. (Isabela, interview)

Cultural awareness. Participants were very aware that there were few to no authority figures at their schools who had the same cultural background as them. It made it harder for Latinos to relate to the culture of the school, which also made more unlikely that they would get involved in school activities. Some participants suggested that more Latino teachers should be hired and that having Latino teachers and staff would provide positive role models. Leon expressed,

Latinos are starting to think that if somebody from a different race is trying to teach them, they won't take it as seriously, but if they find somebody that they can relate to, knowing that they know Spanish and English, I think that they 
would find it more of an "if I can do it, you can too", you know? (Leon, interview)

Others expressed that teachers need to learn about and understand cultural differences, perhaps while they were in their teacher education programs.

Through a teacher program that gets them prepared to work with any class of students especially with those who are having trouble. Just to integrate that into every teacher paying more attention to students, if they're failing help them to improve. And find more help around the school, guide them where to get help. (Eduardo, interview)

Andrea shared that often Mexican students don't have ways of getting involved in activities, either because they don't have the money to pay for extra-curricular activities or because there aren't other Latinos involved. She felt that there should be a concerted outreach to Latinos so they know what's available and how to get involved. She and her friends liked to stay after school to hang-out with friends but didn't usually have anything to do. "Involve people. Because I mean, usually they just stay after school just to hang out and stuff, so why not use that hang out time to do something successful?"

Nayeli too felt facilitating Latino students and families' awareness of options for academic assistance and extra-curricular involvement was important. She -and a few other interviewees expressed-- that "Mexicans just don't do those things".

To make the Latino culture be more aware about education, because there's so much potential and it's just going to waste... all those activities and I do feel that most of the activities, like cheerleading, softball, basketball, not a lot of Hispanics take those activities (Nayeli, interview). 
Outreach. Leon expressed that the only time he saw administrators talking to Latino students was when they were getting in trouble. Therefore, they come to perceive administrators as authoritarian disciplinarians, rather than as resources. Leon and Ariana both thought, that if administrators developed connections with students, it would help Latino students to feel more connected to the school. It would also give administrators a chance to develop relationships with Latino students and develop an awareness of Latino culture.

Connect with students, I think encourage more. Because, I barely saw any administrator going or talking to students. I think they were just there if you got in trouble and not really focused on the education of the student, they were only focused on the bad things you were doing. (Leon, interview)

Isabela thought the school needs to work harder to acculturate and increase the involvement of Latino students. She expressed that being involved in the "fun stuff" would be a way for Latinos to get more acculturated to the main stream culture of the school, and the school more acculturated to Latino student needs.

I think that we need a better integration system throughout the school, so that we're [Latinos] more engaged, so that we're participating in the fun stuff. School then becomes fun, because I had a blast getting involved in my senior year. (Isabela, interview)

Ariana had earlier expressed that when students feel like you don't care about them they're not going to care about doing well. She thought that if administrators took the time to get to know their Latino students that it could be a motivating factor for students. 
Come out of your office. Don't just wait for kids to go to you. You know, come out and take the time and interact with them. Try to interact with them, you know? See what them triggers them, so they can be good, so they can be their best, you know? (Ariana, interview)

Several of the participants expressed that having a class focused on academic support and classes that assisted students prepare for college would be beneficial. These participants explained that while students they worked nights to help their families financially. Also, since their parents weren't able to assist them academically, Eduardo and Julius both thought a study hall during the day would help. Julius: "It would just be nice if they can just have an extra class to help everyone. Whoever needs help, but that class has to be mandatory, like everyone has to take it."

I wish they made another class, but in that class, like study hall, if anyone needs help, they can all get to that one class so they can do their homework there, you know, instead of going home where they don't have help. (Eduardo, interview)

All of the participants expressed that they struggled with knowing how to prepare for college, what to do and even who to ask for help. Leon thought a class available for juniors and seniors that introduced students to applying and what to expect in college was needed.

I think something that would be nice would be have a class be like College 101, telling you just the basic rules of what to expect when - it could even be half a term even also. It could just show you what you should do, like visiting colleges, getting to know what a campus is like (Leon, interview). 
This sense of not knowing was a pervasive theme, not knowing how to prepare academically and not knowing how to participate academically and seemed to impact the participant's sense of being. Participants wanted administrators and teachers to understand this about them and their Latino first and second generation peers.

\section{Summary of Findings}

This result of this research's data collection, by means of interviews and demographic questionnaires, offers significant insights into the complexities of being Latino and a LTEL in high school. The 10 participants shared their perceptions, experiences and reflected on how their school interactions impacted both their development of academic English language and their sense of belonging. Four overarching code family themes emerged, they are: affective needs, acculturation, identity -both as Latino and ELD students- and academic support.

Discussion of the findings is organized through these 4 thematically categorized code families. A summary of these 4 thematic code families, as expressed by the participants, would be lack; a lack of a sense of belonging -which is the crux of affective needs; lack of concerted outreach to Latinos and their families on the part of school administrators or teachers; lack of experiences that were affirming of Latino identities; and finally a lack of academic support. These themes are presented and discussed through employing direct quotes from participant interviews. 
In response to the research questions, the findings of this research discloses that the participants' schools did not support their academic and affective learning needs. The reoccurring themes and patterns from the shared experiences and perspectives of the research participants' interviews support this conclusion. It emerged from the interviews that all of the participants had a sense of being cultural outsiders in high school, and the majority of the participants experienced a lack of academic and acculturative support.

The interviewees also shared suggestions of ways that schools may more effectively serve the academic and affective needs of their bi-cultural EL. Their suggestions regard the culture gap, the need for cultural awareness on the part of administrators, teachers, and staff; and a need for outreach to bicultural students. The participants perceived that the cultural differences between schools in Mexico and the US, their parents' level of formal education, and level of English proficiency were some of the factors that impacted their academic success. The disconnect between the participants home culture and the culture of school necessitates a need for schools to reach out to Latino community, families and students to facilitate the academic success of Latino EL. Chapter 5 discusses the implications of the data. This final chapter provides a review of the research and the major conclusions drawn from the data presented in Chapter 4. Included in Chapter 5 are the findings, implications, and recommendations for educators and school leaders, and suggestions for future research. 


\section{Chapter 5}

\section{Discussion of Findings}

Often educational reforms are enacted from the perspectives of academics and their ideas of what needs to change in classrooms (Cook-Sather, 2002); however there is a dearth of research regarding Long Term English Learners (LTEL) that seeks their perspective on their education. The purpose of this study was to describe and explain recently graduated Latino Long-term English learners' perceptions of the impact of their school's culture on their academic and social acculturation. This research attends to perspectives of recent Latino LTEL students, "Authorizing student perspectives can directly improve educational practice because when teachers listen to and learn from students, they can begin to see the world from those students' perspectives" (CookSather, 2002, p. 3). Data from chapter 4 indicate that work still needs to be done to bridge the educational opportunity gaps that Latino LTEL experience in schools. Listening to and understanding the perspectives of EL students can bring fresh insights of how to bridge the educational opportunity gaps that many young Latino EL fall into.

Objectives of this final chapter are to discuss the findings, explanations, and implications of how school culture impacts the academic acculturation of Latino LTEL students. The findings will be discussed from the perspective of Latino EL and the findings' connection to the relevant research literature. In addition, from the perspective 
of the participants and the research literature, discussed are practical ways educators can preclude perpetuation of academic and culture gaps among Latino EL.

The first section of this chapter summarizes the purpose of the study, research methodology, and the research findings. The findings are presented and supported by available research. The second section discusses the implications of the results and the third section discusses recommendations for secondary teachers and administrators regarding school culture and Latino EL. The fourth section considers the limitations of this research. The final section proposes suggestions for future research.

\section{Summary of the Study}

Understanding the affective learning needs of Latino LTEL is another approach to the issue of LTEL that may help us to positively impact the academic trajectory of LTEL. Krashen's Affective Filter hypothesis and other research (1982), strongly suggests that language learners acquire a second language quicker when their affective filters are low and they feel safe and supported in their learning environment. There is a growing body of research that has established that the status of students' affective needs is an important predictor of students' academic outcomes (Booker, 2007; Chhuon \& Wallace, 2014; Combs, 1982; Faircloth, 2007; Milner, 2002; Oyserman \& Destin, 2010).

In order to give voice to the authority of the Latino LTEL's perspectives and experiences a qualitative research approach was utilized. This qualitative study employed the following data gathering approaches: a demographic questionnaire for 
gathering baseline background information about the participants, and hour-long semistructured one-to-one interviews with 10 former Latino LTEL students. Participants were recruited through teacher referrals, social media, and referrals from their friends. Each participant completed a demographic questionnaire and during the 60 minute interviews were asked 15 questions that were developed in order to find answers to the research questions (Appendix B).

As schools look to improve the educational outcome of Latino EL, listening to voices of former LTEL as they share their high school experiences may provide insights into ways to support the affective learning needs, academic success, and acculturation of Latino EL (Cook-Sather, 2002). Through 10 in-depth interviews with former Latino LTEL and utilizing qualitative coding analysis, this research explored and analyzed recently graduated Latino EL's perceptions of the impact of their school's culture on their development of academic language proficiency. Recognizing the authority of Latino LTEL's voices, experiences and perspectives, this research introduces their perspectives into the conversation about Latino LTEL, and offers what these former LTEL students suggest what could be done to improve Latino EL educational trajectory.

\section{Findings}

The findings of this study were guided by the research questions, the participant's responses to the interview questions, demographic questionnaires, the literature referenced, and the theoretical frameworks utilized as lenses. The results of this research 
explicate that, from the participants' perceptions and experiences, their schools did not support their academic and affective learning needs. This lack of support impacted participants' self-perceptions as learners and scholastic sense of belonging. Recurring themes and patterns emerged from the shared experiences and perspectives of the research participants that support this conclusion. Discussions of these findings are organized through these four thematic code families: Academic support, Acculturation and Affective needs, and Identity.

Academic support. An overarching theme that emerged from the interviews is that while in high school the participants did not feel supported, a sense of belonging, nor did they understand what was expected of them as students for academic achievement. All of the participants expressed that a crux of the issue of academic support is that they and their families did not know how to navigate school structures and requirements. This made the need for access to adult support and school resources even more vital. This lack of access to knowledge of how to navigate school structures perpetuated participants' sense of being an outsider in their schools. The main academic and affective support that all the participants were able to access as students was their ELD teachers. All the participants expressed that their ELD teachers and classes were where they felt comfortable asking questions about school policies and announcements, the school culture, applying to college or accessing academic assistance. 
The first research question seeks to understand participants' perspectives on whether they were academically supported. As we learned from the literature regarding second language development and the literature on learning theories, language learning is complex. Learning happens within school structures that generate micro-cultures of their own (Lave, 1996; Booker, 2007). Generally students are more likely to experience academic achievement in environments where they feel supported, and a sense of belonging (Booker, 2007; Chhuon, \& Wallace, 2014; Collier, 2000; Krashen, 2003; Osterman, 2000).

Several of the participants, who saw themselves as highly motivated in high school, struggled academically because they felt they had no access to academic support, especially in their AP classes. Other participants expressed that there were many times they sat in classes just not understanding what was being taught and often felt shut out of their education because of cultural and language barriers. There was also the issue of how they felt they were perceived, their teachers didn't seem to expect academic rigor or success from them. Interviewees expressed that in Mexico students are not expected to participate as much as expected here in the US, so often they just did not ask questions of their teachers when they didn't comprehend class content. Participants also expressed a sense of shame regarding their accents or language ability as another reason why they did not feel comfortable asking for help within the classroom. As described in the interviews, even when teachers would think to check for comprehension it was often approached in 
ways that would highlight the participants' sense of differentness to a point where it felt it was pointing out academic inferiority.

Acculturation. The major finding in this area of academic support was the lack of outreach from school administrators and many of their teachers. None of the research participants felt that their schools did an adequate job of reaching out to them or their parents. As discussed in chapters 3 and 4, in most cases the participants' parents were not able to assist students academically due to a language barrier. So students, who often did not understand what was going on at school, would be informing their parents about school requirements.

The participant's perspectives were that schools did not take the time to learn enough about their Latino students' culture or background to understand the participants' sense of culture disconnect between their school and home lives. The participants, when it came to navigating school structures, requirements and procedures, didn't even know what they didn't know, hence they didn't know what questions to ask. Without their schools explicitly scaffolding bicultural students' acculturation, as students, these participants ended up feeling like outsiders or failures.

Furthermore, from the participants' perspectives and experiences it appears that their teachers and administrators did not have sufficient professional development or awareness of how to work with Latino and bi-cultural students. The participants' experiences reveal the lack of understanding regarding the acculturative stress that 
students, whose home cultures may be radically different from the culture of their schools, experience. Participants' narratives reveal that they generally felt alienated from their schools. All of the participants main friendships while in school were with other Latinos; they seldom had friends from other cultures and rarely got involved in school activities. The exception to this was when a teacher, usually their ELD teacher or another adult purposefully let them know about opportunities for involvement.

Affective needs. This research's findings are that the participants in this research did not feel a sense of connection, inclusion or feel valued within their schools' culture. As several of the participants pointed out, their schools were still operating under a premise of a homogeneous student population. It seemed to the participants that their school's culture did not represent or try to relate to Latino culture which added to their sense of disconnectedness. One participant expressed the lack of belonging well when she said, "we just weren't part of the team". As they didn't experience a sense of connection to the dominant culture of their schools, the participants developed a subculture with other Latino students. They spoke Spanish and congregated in the hallways of their schools, often in defiance of teachers and administrators wishes. In their first few years of high school most of the participants cut school frequently as school often just left them feeling culturally disconnected and irrelevant. All of the participants did have at least one teacher connection and a couple of them had several positive adult connections. 
All of the participants' main teacher connections were their ELD teachers; they were the teachers they would turn to when they needed assistance.

Prior research indicates that a sense of belonging enhances and supports academic achievement. This too is a conclusion of this research; it finds that students' academic achievement and motivation are impacted by whether and how the participants' affective needs were met. The lack of connection to school and teachers adversely impacted the participants' attitude towards their education and dampened their motivation to succeed academically.

Identity. This research's findings regarding Latino LTEL identity is that as Latinos and ELD students the participants developed a negative academic self-image. The participants' negative academic self-image developed over years in US schools, and was inculcated through school and classroom interactions where, as Latino and ELD students, they were positioned as lower status in relation to their peers. As students, the participants were aware of the cultural differences between the culture of their schools and peers and their home culture. Socio-cultural studies and theory explains that how "students see themselves — as well as any particular group to which they belong-in the context of their school and community can influence students' identity formation, values, feelings of competence and relatedness, and goal-setting" (Usher \& Kober, 2012, p. 6). Because they were self-conscious about their language and cultural differences, the participants were hesitant to get involved in extracurricular activities. The messages these 
former Latino LTEL received about themselves, and their culture group, adversely impacted their sense of academic competence and belonging.

All participants conveyed that as Latinos and ELD students they were perceived by their peers, teachers, staff and administrators to be less competent than other students and/or less respected as learners. They expressed that they were perceived as likely to be in gangs, not serious students and to not finish high school. They experienced regularly that they were treated differently, when it came to discipline, academic expectations and cultural representation. A sense that as ELD students they weren't as “capable" was a repeated refrain when it came to participants' perception of ELD services.

Their schools' culture and preconceptions about Mexicans did not support the participants, as Latino EL students, developing a positive self-identity as serious students. The participants not only had to struggle with cultural differences, their family's struggles to adapt to a new country, but they also had to struggle against negative stereotypes about Mexicans. In their narratives regarding their school interactions 9 of the participants expressed an awareness of: not being treated equally because of their ethnicity; awareness that their peers saw Mexicans as of a lower status; and stereotypes that Mexican students are not academically capable. Research on identity formation indicates that when EL and students from low-income homes strive to become "school successes and want to avoid becoming school failures, they are unlikely to focus sustained effort on school unless contexts support these identities" (Oyserman \& Destin, 2010, p.1021). The majority of participants, as Latinos, did not feel academically 
supported and as ELD students they also contended with their peers and teachers' preconceived notions about their lack of academic ability and their teachers' lack of understanding about how to support them academically.

Limitations of research. The generalizability of this study's findings is limited by several factors. First the small sample size, ten participants. Conducting a similar study with a larger sample size would improve the generalizability. However, this research's participants' profiles and demographics are typical of LTEL profiles discussed in prior research and therefore they have insights that would be applicable in other schools with Latino LTEL of similar demographic profiles. A second limitation, I, the researcher, was known by all of the participants; there is the possibility that if they had not known me that their responses may have been expressed differently. It is also a possibility that because the participants all knew me that they were more comfortable frankly discussing their school experiences than if I was not known to them. Third, the data is based upon participants' recollections and reflection on their school experiences and these recollections may be imperfect. Though in the course of the hour long interviews participants' were able to reflect and remember many experiences that impacted their memories of school. Finally, in qualitative research there is always the possibility of the researcher's biases impacting the implications of the research. In Chapter 3, I outlined the steps taken to counter researcher biases. 
Despite the limitations, this research's findings provide important understandings of the lived scholastic experiences of Latino LTEL. This research provides access to voices of Latino EL and what they have to say about how schools could better serve their Latino EL populations. These findings and recommendations that emerge from the findings can serve to inform educators and researchers of the interventions needed to support the affective and academic learning needs of Latino LTEL.

\section{Significance}

While accountability and measuring student academic growth are significant parts of educating all of our youth, we also need to remember that our schools are communities and incubators of identities. This research points to the importance of supporting our linguistically diverse students developing positive academic identities and positive ethnic identities. In general, the participants of this research experienced that outside of their ELD classes their academic and affective needs were not supported. Instead, the participants, while they were in high school, struggled against devaluing stereotypes of Latinos.

This research supports the importance of EL developing positive relationships with their teachers and school staff. We are expecting EL to navigate a societal institution, which provides a basis for navigating their adult lives, without sufficient scaffolds and interventions. This and prior research conclusively shows that caring and supportive relationships highly and positively impact student's self-perception, 
motivation, and academic success (Chhuon \& Wallace, 2014; Lave, 1996; Norton \& Toohey 2001; Oyserman \& Destin, 2010; Usher \& Kober, 2012). The participant's selfconcept, and their academic and social identities as students' were shaped through their interactions and the contexts within which they occurred.

The findings of this research indicates that, when EL are not able to access assistance with the following: academic learning and educational requirements; academic interaction with their English speaking peers; participation in school activities and the creation of school culture, their academic acculturation and achievement lags. Latino EL students have twice the high school dropout rate of their native English speaking peers. I would argue that this may in large part be due to schools not acculturating, adapting to the cultural mentoring needs of their bi-cultural students, and not attending to their affective needs. It would behoove educators to learn more about the needs and cultures of their EL students. Prior research indicates we cannot bridge education opportunity gaps by seeing education solely as a classroom experience (Lave, 1996; Lopez, 2010; Oyserman \& Destin, 2009; Usher \& Kober, 2012). It would benefit schools to understand the need for cultural bridges to be built into the schools systems and policies to allow for the successful academic acculturation of all of our English Learners. The next section presents recommendations and implications that emerged from the this research's data and it includes recommendations suggested by participants. 
Recommendations and implications for practice. This and prior researcher suggests that schools could benefit EL by taking proactive, concerted steps to assist culturally diverse students' integration into the academic and social culture of their schools. It appears that one of the major hurdles to cultural and academic acculturation of EL is the cultural disconnect experienced by this research's participants and their parents. This sense of cultural disconnect led to the participants not experiencing a connection to school. As prior research has indicated, a sense of belonging is a strong indicator of academic outcomes. This research makes clear that it must be the responsibility of teachers, school, and school districts to provide explicit and concerted access to that sense of belonging for bi-cultural and EL students. We cannot expect EL and their parents to know how to access resources and assistance in a culture that is new and equally foreign to them.

Recommendations and implications for classroom culture. Teachers of EL and Latino LTEL need to recognize and understand that the home lives of many EL are culturally distinct from their culturally main stream peers. If we do not facilitate a sense of belonging, this and prior research indicates that students can end up feeling alienated and developing negative academic identities as a result of their day-to-day school interactions. Several of the participants discussed their embarrassment at their Latino accents and how their embarrassment caused them to not want to participate verbally in class. Again, the culture of a school and how it is curated by school leaders, classroom 
teachers and other staff, sets the tone that allows a sense of shame about being culturally different to originate and develop (Li, 2010; Oyserman \& Destin, 2010; Urrieta, 2007).

The data from the interviews indicate participants did not engage in sufficient scaffolded academic dialogue with their native speaker peers in their core classes while in high school. From the data this seems to be a result of their core and elective teachers not knowing how to engage and support EL in their classes. It seems that even in some of their core classes participants were grouped together with other EL which further isolated them from sustained academic discourse with native speakers during collaborative work. Grouping EL together in a class may also disrupt their opportunities to develop academic relationships with native speaking peers.

Recommendations and implications for school culture. A recommendation suggested by many of the participants is the importance of educating staff and teachers about the cultures of their EL, and for teachers, administrators and school staff to consider how they perceive and treat Latino and bi-cultural students. Many of the participants' narratives expressed that as Latino students they were viewed and ended up viewing themselves as lower-status students. This perception was fueled by the participants' lack of knowledge about school culture and their teachers' lack of knowledge about their students' cultures. Not only do we need to make sure that our programs for teachers address the needs of bi-cultural students, in-service professional development for practicing educators is also needed. 
It appears from the interviews that in high schools immigrants and EL are mainly seen as the concern of their ELD departments. EL and bi-cultural students' academic acculturation needs to be recognized as everyone's concern, and all teachers need to be trained to address the affective and academic needs of this growing population of EL and LTEL. This research points to the importance of students developing positive relationships with their teachers and other adults at school. Developing these relationships would also benefit educators through having the opportunity to get to know students from other cultures and learn a little about their scholastic reality. A concerted effort should be made to foster EL connections, possibly through mentoring programs with older students, community organizations, and having LTEL work as assistants in their core teachers' classes. These relationships could facilitate positive academic identities and positive acculturation of EL and their school community.

All of the research participants attended school in Oregon, a recently culturally diversifying state and within a school district where there appears to be a deficit of understanding of the affective and academic needs of non-European immigrant student groups. The perspective of many of the participants was that schools need to develop newer school traditions and pathways for inclusion that are welcoming to bi-cultural students. These pathways could include announcements spoken and printed in other languages, Latino student focus groups with administrators, advisory sessions, schools acknowledging and representing the many languages that are now found in their schools, and concerted and on-going outreach to bi-cultural families. 
Nationwide school demographics are changing and to bridge achievement and culture gaps it's necessary that our schools consciously acculturate to be welcoming to a diversity of cultures. Structuring into the culture of school a forum that attends to the voices, experiences and perceptions of El and Latino LTEL would be a way for administrators to reach out to their bi-cultural and EL students. The participants categorically expressed their lack of connection to school administrators. A few of the participants had had experiences where their views as Latinos were sought, and it was an affirming experience for them.

All of the participants recommended that more Latino adults are needed in schools as mentors and exemplars of what is possible for Latino students to accomplish. It's important that all students see adults of color in positions of authority working in their schools in order to create a school culture that supports and recognizes crosscultural achievement. As Latinos, the participants all experienced a sense of cultural alienation from school, a distinct sense that their culture wasn't represented in their high school. It is obvious to say we need more teachers of color in our schools, and as we work towards that goal, what we really need to do is create schools where Latino students thrive academically and are inspired to become educators. This is more likely to happen when Latino students have positive connections with their teachers and administrators.

Recommendations and implications for school district administrators. This research supports the work of critical socio-cultural theorists such as Li who in her 2010 study of Chinese immigrants in Canadian schools, explains how the acculturation needs 
of our immigrant and children of immigrant students challenge our schools to be places where cultural integration is supported ( $\mathrm{Li}, 2010)$. Our schools need to acculturate to the changing faces of our classrooms.

School and district outreach to Latino students and their families would be an effective approach to reframe the ways Latino LTEL and their families perceive and interpret their relationships with their schools, core teachers and peers. The participants expressed that as Latinos they didn't feel that disciplinary measures were equally meted out. Their perceptions were that many of the adults at their schools seemed to have negative preconceived ideas about Latinos, and administrators approached their interactions with Latino students assuming culpability. Many of the participants suggested that to counter negative stereotypes about Latinos administrators take time to get to know their bi-cultural students and reach out to their families as well. Events such as family nights for Spanish speakers, college fairs in Spanish, and other events that give students and their families' access to and knowledge about navigating school and US culture would facilitate inviting these students and their families into the school culture. Such practices would also help schools to proficiently adapt and acculturate to a diversifying student body.

Recommendations and implications for ELD teachers. Finally, the data from these interviews make clear that for EL and Latino LTEL, ELD departments are often their home base in their schools. Their ELD teachers are where ELs' academic and affective needs are being met. All of the participants expressed that their ELD teachers 
were academic resources who encouraged them to apply to college. It is notable that a majority of the participants, nine, had taken at least one college class. Unfortunately, of those nine only two have thus far continued beyond a second semester of college.

Unfortunately, it seems all of the participants experienced negative stereotypes associated with being EL and receiving ELD support. This again addresses the culture of the school; this indicates that ELD services are being provided and/or framed socioculturally in a way that invites negative connotations. For example, EL services are often labeled as a deficit, as when we refer to English learners as Limited English Proficient (LEP). Schools could reframe bilingualism and biculturalism as desirable assets that all learners should want to attain. Within the school culture this reframing could help with teachers' and other students' perceptions of English Learners.

\section{Suggestions for further research}

This research points to the necessity of addressing the affective learning needs of EL and facilitating their acculturation and participation within the culture of the school. However, this research was conducted with a small sample size of participants, 90 percent of whom attended high schools in one school district; hence, in order to determine the generalizability of the findings of this study, further research is needed. A mixed methods research that involves Latino LTEL from different school districts, regions, and states would allow researchers to compare a farther-reaching range of Latino 
LTEL perceptions of how their affective needs were met and whether they were supported in their academic acculturation while in high school.

A mixed methods study that includes a survey and focus groups of EL students in middle school, who are not yet considered LTEL, could uncover whether these younger students also experience a sense of not belonging within their school's culture. Understanding if this sense of otherness in relation to school is something that develops over time or is there from when Latino EL begin school would provide valuable data and understandings about the EL scholastic experience that could be applied to classroom teachers' and administrators' practice.

Critical pedagogy posits that education can be liberatory for students of nondominate cultures when we incorporate their views and voices in school reforms. This research considered the experiences and perceptions of Latino LTEL, future research that explores the experiences and perceptions of LTEL of different ethnic backgrounds could shed light on how LTEL from diverse cultures experience their places within their schools. In applying a critical lens to the academic acculturation of Latino LTEL and LTEL from other non-dominant culture groups, further research on ways to authentically represent the voices of LTEL and EL into the culture of schools could provide pathways to students developing a positive academic self-identity. As well, this type of research could point to ways schools may more effectively acculturate and serve their diversifying student populations. 


\section{Summary and conclusion}

This research points to the importance of supporting our bi-cultural students in developing positive academic and ethnic identities. Acculturation, how schools meet the academic, social, and affective needs of students from different cultures and how they approach helping students to integrate into the school environment, impacts Latino EL's academic and ethnic self-perception. This research contributes to the body of research regarding Latino LTEL by presenting the perspectives of participants who have recently been Latino LTEL. This research indicates that students' sense of belonging is a key element in student academic achievement. The majority of this research's participants did not feel a sense of connection to school. For their sense of belonging in school the participants' friendships were almost exclusively with other Latino and EL students and for this they were often labeled as gang members, or troublemakers.

English Learners' and bi-cultural students' pathways to academic success not only need to be supported, schools need to make sure that the school's cultural impediments to EL's academic acculturation are recognized and addressed. English Learners and bicultural students have explicit needs in order to acculturate to school culture, and their schools have a responsibility to understand the cultures of their non-European immigrant students so they may provide a supportive school environment. Educators can ameliorate inequitable educational outcomes experienced by Latino LTEL students, not only by attending to their students' literacy needs, but also, by teaching Latino EL how to 
navigate cultural relations and differences. Working with EL students within their schools; valuing what they have to say about their scholastic experiences; and providing opportunities for input into school culture and processes, such practices may engender Latino EL participation in the production of the school's culture.

This research project employed two theoretical frameworks socio-cultural theory and critical pedagogy. These theoretical stances were used to frame an understanding of how meeting students' affective needs can impact their academic proficiency. The participants' experiences reveal how a sense of not belonging to their school's community impacted their academic outcomes and self-perceptions. Schools are where we are all acculturated into social and civic ways of being. Socio-cultural theory reminds us that, students' developing identities as learners are formed through all of their interactions within their schools and daily. Our Latino LTEL students are bi-lingual and bi-cultural, schools must consciously make transparent cultural processes and norms so that students and their families may learn to navigate school culture. Critical pedagogy posits that schools can empower students and transform the subtle features of inequity that permeate LTEL students' everyday classroom experience. Validating the voices and experiences of our Latino EL students can provide schools opportunities to transform those features of inequity that are invisible to those of us from the dominant culture and bridge the achievement and culture gap in which many high school Latino LTEL find themselves wedged. 


\section{References}

Aronson, J. (2004). The threat of stereotype. Educational Leadership, 62(3)14-19.

Berry, J.W (1997). Lead article: Immigration, acculturation, and adaptation. Applied Psychology: An International Review, 46 (1) 5-68.

Berry, J. (2003). Conceptual approaches to acculturation. In Chun, K. M.; Balls, O.; Marín, G. (Eds), Acculturation: Advances in theory, measurement, and applied research, (pp. 17-37). Washington, DC: American Psychological Association.

Berry, J.W. (2005). Acculturation: Living successfully in two cultures. International Journal of Intercultural Relations, 29 (6), 697-712.

Bolman, L.G. \& Deal, T. (2008). Reframing organizations. San Francisco, CA: Jossey-Bass.

Booker, C. (2007). Likeness, comfort, and tolerance: Examining African American adolescents' sense of school belonging. Urban Review 39, (3). 301-317

Brown, S. B., Collins, A. \& Duguid, P. (1989). Situated cognition and the culture of learning Educational Researcher, 18 (1), 32-42.

Calhoun C. (1994). Social theory and the politics of identity. Oxford: Blackwell.

Chapman, C., Laird, J., \& KewalRamani, A. (2010). Trends in High School Dropout and Completion Rates in the United States: 1972-2008. Compendium Report. NCES 2011-012. National Center for Education Statistics.

Chhuon, V., \& Wallace, T. (2014). Creating connectedness through Being Known: 
Fulfilling the need to belong in U.S. high schools. Youth and Society, 46 (3), 379401.

Collier, V.P. (1995). Acquiring a second language for school. Directions in Language and Education, 1(4).

Collier, V.P., \& Thomas, W.P. (1989). How quickly can immigrants become proficient in school English? Journal of Educational Issues of Language Minority Students, 5, 26-38.

Combs, A.W. (1982). Affective education or none at all. Educational Leadership. 39 (7), 494-498.

Cook-Sather, A. (2002). Authorizing students' perspectives: Toward trust, dialogue, and change in education. Educational Researcher, 31 (4), 3-14.

Cummins, J. (2000). Language, Power and Pedagogy: Bilingual Children in the Crossfire. Clevedon, Great Britain: Multi-Lingual Matters Ltd.

Dalton, S. \& Sison, J. (1995). Enacting instructional conversation with Spanish speaking students in middle school mathematics. UC Berkeley: Center for Research on Education, Diversity and Excellence.

Darling-Hammond, (2006). Constructing 21st-century teacher education. Journal of Teacher Education, 57 (3), 300-314.

Delpit, L. (1995). Other people's children: Cultural conflict in the classroom. New York: The New Press.

Deters, P. (2011). Identity, Agency and the Acquisition of Professional Language and 
Culture. NY, NY: Continuum International Publishing Group.

Donato, R. and MacCormick, D. (1994). A Sociocultural perspective on language learning strategies: The role of mediation. The Modern Language Journal, 78(4), 453-464.

England, L. (1982). The role of integrative motivation in English as second language learning among a group of foreign students in the United States. Presented at the Annual convention of TESOL , (16 ${ }^{\text {th }}$, Honolulu, HI, May 1-6, 1982).

Ernst, P. (1997). Reflections on theories of learning. ZDM, 38 (1).

Faircloth, B. S. (2009). Making the most of adolescence: Harnessing the search for identity to understand classroom belonging. Journal of Adolescent Research, 24 (3), 321-348.

Faircloth, B. S., \& Hamm, J. V. (2005). Sense of belonging among high school students representing four ethnic groups. Journal of Youth and Adolescence, 34, 293-309.

Faltis, C., \& Coulter, C. (2008). Teaching English learners and immigrant students in secondary school. Upper Saddle River, NJ: Pearson Education Inc.

Forrest, S. (2006). Three foci of an effective high school generation 1.5 literacy program. Journal of Adolescent and Adult Literacy, 50(2), 106-112.

Fosnot, C.T. (1996). Constructivism: Theory, perspectives, and practice. New York: Teachers College Press.

Fowler, F. (2004). Policy studies for educational leaders: An introduction. New Jersey: Pearson. 
Frey, W. (1998). Immigration concentration and domestic migrant dispersal: Is movement to non-metropolitan areas white flight? Professional Geographer, $50(2), 215-232$.

Friere, P. (1970). Pedagogy of the oppressed. N.Y: Herder \& Herder.

Gans, (1997). Toward a reconciliation of "Assimilation" and "Pluralism": The interplay of acculturation and ethnic retention. International Migration Review, 31(4) 875892.

Garcia-Vasquez, E. (1995). Acculturation and academics: Effects of acculturation on reading achievement among Mexican-American students. The Bilingual Research Journal, 19 (2) 305-315.

Giang, M and Wittig, M. (2006). Implications of adolescents' acculturation strategies for personal and collective self-esteem. Cultural Diversity Ethnic Minority Psychology, 12 (4), 725-739.

Gibson, M. (1997). Introduction: exploring and explaining the variability: Cross-national perspectives on the school performance of minority students. Anthropology \& Education Quarterly, 28 (3), 318-329.

Gitlin, A.,Buendid, E., Crossland, K., \& Doumbia, F. (2003). The production of margin and center: The welcoming -unwelcoming of immigrant students. American Educational Research Journal, 40 (1), 91-122.

Glaser, B.G., \& Strauss, A.L. (1967). The discovery of grounded theory: Strategies for qualitative research. Aldine Transaction, New Brunswick. 
Goldschmidt, M. M., \& Miller, C. Z. (2005). Beyond the academic needs of generation 1.5. Research and Teaching in Developmental Education, 21 (2), 10-19.

Gutiérrez, K.D., \& Orellana, M. F. (2006). At last: The" problem" of English Learners: Constructing genres of difference. Research in the Teaching of English, 40(4), 502-507.

Harklau, L.(2003). Generation 1.5 students and college writing. CAL/ERIC Digest. October.

Hakuta, K. (2000). How long does it take English learners to attain proficiency? University of California Linguistic Minority Research Institute.

Hinde, E. R. (2004). School culture and change: an examination of the effects of school culture on the process of change. Essays in Education, 12, 725-739.

Hungerford-Kresser, H., \& Vetter, A. (2012). Positioning and the discourses of urban education: A Latino student's university experience. The Urban Review, 44,120.

Jiménez, R. T. (2000). Literacy and the identity development of Latina/o students. American Educational Research Journal, 37(4), 971-1000.

Krathwohl, D.R. (2009). Methods of educational and social science research. Long Grove, Illinois: Waveland Press.

Krashen, S.D. (1982). Principals and Practice in Second Language Acquisition. Oxford, England: Pergamon Press. 
Lalas, J. \& Valle, E. (2007) Social justice lenses and authentic student voices: Enhancing leadership for educational justice. Educational Leadership and Administration, 19, 75-10.

Lantolf, J.P. (1994). Sociocultural Theory \& Second Language Learning: Introduction to the special issue. Modern Language Journal, 78 (4), 418-420.

Lavadenz, M. (2010). From theory to practice for teachers of English Leaners. The CATESOL Journal, 22(1), 18-47.

Lavadenz, M., Armas M., \& Barajas, R. (2012). Preventing Long-Term English Learners: Results of a Project-Centered, Differentiated ELD Intervention Program. $C A B E$ Conference Edition. 2012.

Lave, J. (1996). Teaching, as learning, in practice. Mind, Culture, and Activity, 3 (23), 149-164.

Li, J. (2010). 'My home and my school': Examining immigrant adolescent narratives from the critical sociocultural perspective. Race, ethnicity and education 13 (1), 119-137.

Lopez, F. (2010). Identity and motivation among Hispanic English language learners in disparate educational contexts. Education Policy Analysis Archives, 18 (16), 1-33.

Marshall, C. \& Gerstl-Pepin, C. (2005). Re-framing educational politics for social justice. Boston: Pearson.

Maxwell, J. (2005). Qualitative research design: An interactive approach. CA: Sage Publications. 
McLaren, P (2003). Life in schools: An introduction to critical pedagogy in the foundations of education. ( $4^{\text {th }}$ edition) Boston, MA: Allyn \& Bacon.

Mehan, H., Hubbard, L., \&, Villanueva, I. (1994). Forming academic identities: Accommodation without assimilation among involuntary minorities. Anthropology \& Education Quarterly, 25(2), 91-117.

Merriam, S. (2009). Qualitative Research. San Francisco, CA: Jossey-Bass.

Milner, R. (2002): Affective and social issues among high achieving African American students: Recommendations for teachers and teacher education. Action in Teacher Education, 24 (1), 81-89

Norton, B., \& Toohey, K. (2001). Changing perspectives on good language learners. TESOL Quarterly, 35 (2), 307-322.

Ogbu, J. (1993). Differences in cultural frame of reference. International Journal of Behavioral Development, 16 (3), 483-506.

Olsen, L. (2010). Reparable harm: Fulfilling the unkept promise of educational opportunity for California's long term English learners. Beach, CA: Californians Together. Retrieved from www.californianstogether.org.

Olsen, L., \& Wan, Y. (2010). A closer look at Long Term English learners: A focus on new directions. The Starlight, 7.

Osterman, K. (2000). Students' need for belonging in the school community. Review of Educational Research Fall, 70 (3), 323-367

Oyserman, D., \& Destin, M. (2010). Identity-based motivation: Implications for 
intervention. The Counseling Psychologist, 38, 1001-1043.

Peguero, A. (2010). A profile of Latino school-based extracurricular activity involvement. Journal of Latinos and Education, 9 (1), 60-71.

Peterson. R. (2003). Teaching how to read the world and change it: Critical pedagogy in the intermediate grades. The Critical Pedagogy Reader. Ruttledge. 365-387.

Petersen, K. \& Deal,T. (1998). How leaders influence the culture of schools. Educational Leadership, 56 (1), 28-30.

Portes, A. (1997). Immigration theory for a new century: Some problems and opportunities. International Migration Review, 21(4), 799-825.

Ray, M. (2003). A tale of two cities: The role of place in ethnic acculturation (Masters Thesis, University of Oregon).

Roland, K. (2008). Educating for inclusion: Community building through mentorship and citizenship. Journal of Educational Thought, 42 (1), 53-67.

Rubin, B. (2007). Learner identity amid figured worlds: Constructing (in) competence at an urban high school. The Urban Review, 39 (2), 217-249.

Rumbaut, R. (1999). Immigration research in the United States: Social origins and future orientations. The American behavioral scientist, 42 (9), p. 1285-1301.

Saldana, J. (2009). The coding manual for Qualitative Researchers. Thousand Oaks, CA: Sage Publications.

Schumann, J. (1986). Research on the acculturation model for second language acquisition. Journal of Multilingual \& Multicultural Development, 7( 5), 379-392. 
Sfard, A. (1998). On two metaphors of learning and the dangers of choosing just one. Educational Researcher, 27(2), 4-13.

Spencer, M. (1999). Social and cultural influences on school adjustment: The application of an identity-focused cultural ecological perspective. Educational Psychologist, 34(1), 43-57.

Spenader, A. J. (2011). Language learning and acculturation: Lessons learned from high school and gap year exchange students. Foreign Language Annals, 44(2), 381398.

Steele, C. M., \& Aronson, J. (1995). Stereotype threat and the intellectual test performance of African Americans. Journal of Personality and Social Psychology, 69, 797-811.

Trimble, J. E., (2003). Introduction: Social change and Acculturation. In Chun, K. M., Organista, P. B., \& Marín, G. (Eds.), Acculturation: Advances in theory, measurement, and applied research (pp.3-13) Washington, D.C: American Psychological Association

Tyler, K., Uqdah, A., Dilihunt, M., Beatty-Hazelbaker, R., Conner, T., Gadson, N,. Henchy, A., Hughes, T., Mulder, S., Owens, E., Roan-Belle, C., Smith, L., Stevens, R. (2008). Cultural Discontinuity: Toward a Quantitative Investigation of A major Hypothesis in Education. Educational Researcher, 37(5), 280 -297.

Urrieta, L. (2007). Figured worlds and education: An introduction to the special issue. The Urban Review. 39 (2), 107-116 
US Department of Education: Office for Civil Rights. (2012). Developing Programs for English Language Learners: Legal background. http://www2.ed.gov/about/offices/list/ocr/ell/legal.html

US Department of Education: Office for Civil Rights, (2013). The provision of an equal education opportunity to Limited-English Proficient students. http://www2.ed.gov/about/offices/list/ocr/eeolep/index.html

Usher, A., \& Kober, N. (2012). 4. What Roles Do Parent Involvement, Family Background, and Culture Play in Student Motivation? Center on Education Policy. http://eric.ed.gov/?id=ED532666.

Vagan, A. (2011). A sociocultural perspective on identity formation in education. Mind, Culture and Activity, 18(1), 43-57.

Valdes, G. (2001). Learning and not learning English: Latino students in American schools. N.Y. NY: Teachers College Press.

Valenzuela, A, (1999). Subtractive schooling: US-Mexican youth and the politics of caring. NY, NY: Suny Press.

van den Berg, G. C. S., \& Jiang, Y. (1998). Cross-cultural adaptation and ethnic communication: Two structural equation models. Howard Journal of Communication, 9(1), 69-85.

Van Oudenhoven, J. P., Ward, C., \& Masgoret, A. M. (2006). Patterns of relations between immigrants and host societies. International Journal of Intercultural Relations, 30(6), 637-651. 
Volet, S.J. (1997). Affective and cognitive variables in learning: The significance of direction and effort in student goals. Learning and Instruction. 7 (3), 235- 254.

Vygotsky, L. S. (1962). Thought and Language, edited and translated by E. Hanfmann and G.Vakar.

Wenger, E. (1998). Communities of Practice: Learning ,Meaning and Identity. Cambridge, UK: Cambridge University Press.

Whitlock, J. (2006). Youth perception of life at school: Contextual correlates of school Connectedness in adolescence. Applied Developmental Science, 10(1), 13-29.

Zen, D. (2001). What is wrong with ESL programs in schools? (Conference Paper Washington, D.C.: Educational Resources Information Center. (ED482580). 


\section{Appendix A}

\section{Participant Informed Consent}

The Affective Learning Needs of Latino Long-term English Language Learners

You are invited to participate in a research study conducted by Maureen Ray as part of her dissertation work as a graduate student in the Graduate School of Education at Portland State University. This researcher hopes to learn more about how Latino students, who were in English Language Learner programs while they were in high school, feel about their high school experience. You were selected as a possible participant in this study because of your history as an ELL student while you were in high school.

If you decide to participate, you will be asked to engage in a 30- 60 minute audiorecorded interview with Maureen Ray, at a designated location. You will be asked to fill out an emailed questionnaire before the interview. Approximately one month later, if you choose to, you will be invited to participate in a focus group conversation that will a group of approximately 10 students and last for one hour. If you prefer not to be interviewed, you can still choose to participate by filling out the survey and attending the focus group discussion. Or you may choose to do the interview but not the focus group discussion. Interviews will be scheduled at the convenience of participants. All audio recordings be transcribed utilizing pseudonyms, and then the audio erase

You may not receive any direct benefit from taking part in this study, but the study may help to increase knowledge in the field that may help other educators in the future

Any information that is obtained in connection with this study and that can be linked to you or identify you will be kept confidential through use of a pseudonym. The pseudonym will be used to label all information collected and will be used in written 
reports. Your participation is completely voluntary. You may also withdraw from this study at any time without affecting your relationship with Portland State University, the school district, and the researcher. However, confidentiality cannot be guaranteed in a group setting, and participants will be requested to not share the content of the focus group outside of the research setting.

During the interviews and focus group questions regarding potentially personal experiences such as language skills, national origin, race/ethnicity, or institutional bias in education will be discussed. If you think you may feel uncomfortable discussing these topics you are free to decline participation.

As well if you have concerns or problems about your participation in this study or your rights as a research subject, please contact the Human Subjects Research Review Committee, Office of Research and Sponsored Projects, Market Center Bldg Room 620, Portland State University, (503) 725-4288.

Your signature indicates that you have read and understand the above information and agree to take part in this study. Please understand that you may withdraw your consent at any time without penalty, and that, by signing, you are not waiving any legal claims, rights or remedies. The researcher will provide you with a copy of this form for your own records. Please put a check mark next to the activities that you are consenting to participate in.

○ Interview with Maureen Ray

O One hour focus group

Name

Signature

Date 


\section{Appendix B}

\section{Questions for semi-structured interviews}

1. Tell me about your high school experience.

2. Tell me about a teacher who was supportive of your academic growth.

3. Tell me about a teacher who wasn't supportive of your academic growth.

b. how could they have been more supportive?

4. How long were you in an ELD program?

a. How was the program supportive of your social growth?

b. How was the program supportive of your academic growth?

c. Explain how you feel it has it helped you.

d. Explain how you feel it may have hindered you.

5. Tell me about your friends in high school.

b. Did you have friends who were from other ethnicities?

6. How would you describe your sense of feeling part of your school?

7. How did your participation in an ELD program affect how others viewed you?

b. What about teachers?

8. How did being Latino/a affect how other students viewed you?

b. What about teachers?

c. Were adults, at your school (s), supportive of Latino culture being expressed at school? Give me an example?

9. Do you think you were prepared for college after graduating high school? Explain

10. Did you feel comfortable speaking Spanish at school?

11. Do you think the school treats Latinos fairly? Give me an example.

12. Were adults at school available to help you? What about other Latinos? 
13. Who at school took time to make sure you knew how to navigate school rules and procedures? Give me an example.

14. How could the high school you attended better serve the needs of their English Language Learners?

15. What would you tell a high school administrator to help them provide a socially and supportive environment for their Latino ELL students? 


\section{Appendix C}

\section{Questionnaire}

1. Name

2. Age :

3. Gender: Circle one. Male Female Prefer not to say

4. What is your ethnicity?

5. How would you describe the socioeconomic status of your family? How frequently do you speak a language other than English at home? Circle one.

English Only Mostly English Mostly Spanish Spanish Only

7. Do your read and/or write in Spanish?

8. If you were not born in the US, when did you come to the United States? To which state ?

10. How old were you when you started speaking English?

11. What year did you graduate high school? How many years did you attend high school?

12. Were you still participating in an ELL program your senior year of high school? 
13. What would you say was your GPA upon high school graduation?

14. Did you attend college after high school?

If yes how many years?

15. Have any of your siblings attended college? Circle one. Yes No

16. What is your parent's educational background? 


\section{Appendix D}

\section{Email Recruitment Letter}

Dear

You are invited to participate in a research study that I am conducting as part of my research as a graduate student in the Graduate School of Education at Portland State University. I am contacting you to see if you would like to participate in this study because of your history as an ELL student while you were in high school. I want to know how schools could be more welcoming to Latino students and how to facilitate ELs feeling part of the school culture

If you decide to participate, you will be asked to take part in a 30- 60 minute audio-recorded semi structured interview with me, at a location of your choice, for example a coffee shop or a room reserved at the PSU library. I will share the interview questions with you beforehand so you'll have a chance to look over them. It is also possible to conduct the interview over the telephone. During the interview, I will be asking you about your high school experiences. I will audio record the interviews.

Approximately one month after the interview, you will be invited to participate in a focus group conversation with a group of approximately 5-8 other participants. This group conversation/interview will last for approximately one hour. The location of the focus group will be at Portland State University. 
If you prefer not to be interviewed, you can still choose to participate by attending the focus group discussion. Or you may choose to do the interview but not the focus group discussion. Interviews will be scheduled at your convenience.

If you decide to participate you will sign a required consent form that outlines how your confidentiality will be assured. No one, besides me and the participants, will know the identity of participants. Focus group participant confidentiality cannot be guaranteed in a group setting, and it will be requested that participants not share the content of the focus group outside of the research setting.

The results of the interviews will be used for my dissertation, and they also may be used in presentations about ways that English Language Development programs and secondary schools could help better assist Latino ELL students.

I hope you decide to participate, I think we can have some very interesting conversations about what it is like to be a Latino English Language Learner.

I look forward to hearing from you.

Please contact me at maureenr@pdx.edu, leave me your phone number and or email and I will contact you to set up an appointment.

Sincerely,

\author{
Maureen Ray \\ maureenr@pdx.edu
}




\section{Appendix E}

\section{Code Families With A List Of Their Codes And Number Of Quotes}

\section{Code Family: Academic support}

Comment: did the participant feel ready for school upon graduation, did they know while they were in school, did they attend college?

Codes (10): [-lack of connection to teachers] [+ ELD support] [+perception of ELD] [academic advice] [academic preparedness] [academic support] [classroom connection] [lack of academic support] [not prepared for college] [positive experience with eld program]

Quotation(s): 44

\section{Code Family: Acculturation}

Comment: Codes that refer to the school adapting and supporting Latino student's adaptation and the school adapting to the needs of Latino students. Access to resources that helped them navigate school system and culture.

Codes (34): [-lack of access to resources] [-lack of connection to school culture] [-lack of connection to teachers] [-lack of support] [-perception of Latinos] [relationships with teachers] [-school connection] [-unfair treatment of Latinos discipline] 
[+ belonging] [+ ELD support] [+involvement] [+multicultural club involvement $]$ [+perception of ELD] [+school connection,] [+school support] [+teacher connections] [academic advice] [academic preparedness] [academic support] [equity] [feeling unrepresented] [feeling valued] [fighting against latino stereotypes] [idioms] [involvement and representation] [lack of academic support] [lack of connection] [negative relationship with teacher] [negative stereotype of ELD] [no school connections] [not feeling valued] [racism] [school belonging] [school connections]

Quotation(s): 115

\section{Code Family: Affective needs met +}

Comment: Codes that indicate that students felt a sense of belonging and connection to school. Having resource people at their that they knew they could turn to, a sense of meaningful connection.

Codes (17): [-lack of access to resources] [-lack of connection to school culture] [+ ELD support] [+school support] [+teacher connections] [classroom connection] [creating connections] [feeling valued] [not feeling valued] [perceived lack of support for students who were struggling] [perception that help not equally available to Latinos] [relationship at school] [school belonging] [school connections] [school involvement] [sense of belonging/eld] [teacher connections]

Quotation(s): 63 


\section{Code Family: Identity}

Comment: Identity: how the students see themselves in relation to school, through school interactions.

Codes (35): [-Latino culture not represented] [-not to speak Spanish] [perception of Latinos] [-school connection] [-unfair treatment of Latinos discipline] [_speaking spanish] [+Latino culture represented] [+multicultural club involvement] [+perception of ELD] [+school support] [academic preparedness] [Eld main friends] [feeling unrepresented] [feeling valued] [fighting against latino stereotypes] [involvement and representation] [lack of academic support] [lack of connection] [Latino culture not represented] [Latino friends] [negative stereotype of ELD] [no school connections] [not feeling valued] [not prepared for college] [perception of eld students] [perception that help not equally available to Latinos] [positive perception of latinos teachers] [racism] [relationship at school] [relationships] [school belonging] [sense of belonging/eld] [speaking spanish at school] [struggling with issues of racism] [teacher connections]

Quotation(s): 75 